\title{
Immune-checkpoint inhibitors for combating T-cell dysfunction in cancer
}

This article was published in the following Dove Press journal:

OncoTargets and Therapy

\author{
Ewelina Grywalska' \\ Marcin Pasiarski $i^{2,3}$ \\ Stanisław Góźdż ${ }^{3,4}$ \\ Jacek Roliński' \\ 'Department of Clinical Immunology \\ and Immunotherapy, Medical \\ University of Lublin, Lublin, Poland; \\ ${ }^{2}$ Department of Hematology, Holy \\ Cross Oncology Center of Kielce, \\ Kielce, Poland; ${ }^{3}$ Faculty of Health \\ Sciences, Jan Kochanowski University, \\ Kielce, Poland; ${ }^{4}$ Department of \\ Oncology, Holy Cross Oncology \\ Center of Kielce, Kielce, Poland
}

Correspondence: Ewelina Grywalska Department of Clinical Immunology and Immunotherapy, Medical University of

Lublin, Chodzki 4a, 20-093 Lublin, Poland

Tel +48814486420

$\mathrm{Fax}+48814486421$

Email ewelina.grywalska@gmail.com

\begin{abstract}
Under normal conditions, the immune system responds effectively to both external and internal threats without damaging healthy tissues. Cells undergoing a neoplastic transformation are one such threat. An efficient activation of T cells is enabled by T-cell receptor (TCR) interactions with antigen-presenting class I and class II molecules of the major histocompatibility complex (MHC), co-stimulatory molecules, and cytokines. After threatening stimuli are removed from the body, the host's immune response ceases, which prevents tissue damage or chronic inflammation. The recognition of foreign antigens is highly selective, which requires multistep regulation to avoid reactions against the antigens of healthy cells. This multistep regulation includes central and peripheral tolerance toward the body's own antigens. Here, we discuss T-cell dysfunction, which leads to poor effector function against foreign antigens, including cancer. We describe selected cellular receptors implicated in T-cell dysfunction and discuss how immune-checkpoint inhibitors can help overcome T-cell dysfunction in cancer treatment.
\end{abstract}

Keywords: B- and T-cell lymphocyte attenuator, cytotoxic T-cell antigen 4, lymphocyteactivation gene 3 , programmed cell death protein 1, T-cell exhaustion, T-cell immunoglobulin and mucin domain 3, checkpoint inhibitors

\section{Introduction}

Complex immune mechanisms enable the differentiation between self and non-self so that the immune response can be effectively directed at foreign antigens, such as cancer cells, and does not damage the body's own healthy tissues. The immune system recognizes certain antigens as own due to both central and peripheral tolerance. Similarly, full activation of the immune system against foreign antigens is precisely regulated and requires several signals. ${ }^{1}$ An efficient activation of T cells is enabled by T-cell receptor (TCR) interactions with the antigen-presenting class I and class II molecules of the major histocompatibility complex (MHC) (signal 1), co-stimulatory molecules (signal 2), and cytokines (signal 3). ${ }^{2}$ This multistep regulation enables termination of the immune response when threatening stimuli are removed from the body.

Here, we discuss the role and mechanisms of T-cell dysfunction in cancer, which leads to immune evasion by cancer cells and, thus, to cancer progression. ${ }^{3,4}$ We describe cellular receptors implicated in T-cell dysfunction and discuss how immune-checkpoint inhibitors can help overcome T-cell dysfunction in cancer treatment.

\section{Immune evasion in cancer due to T-cell dysfunction}

The complex cross talk between cancer cells, immune cells, and tumor microenvironment involves many mechanisms that lead to an inefficient immune response toward cancer cells. In cancer, T-cell dysfunction may be due to T-cell exhaustion, T-cell anergy, 
decreased phosphorylation of the $\mathrm{CD} 3 \zeta$ chain, and inhibitory signaling within the tumor microenvironment.

Continuous TCR stimulation in effector T cells gradually leads to exhaustion of these cells, which occurs mostly in chronic viral infections and cancer. ${ }^{5}$ Due to T-cell exhaustion, cytotoxic lymphocytes lose their effector function, which leads to an impaired immune response. T-cell exhaustion develops more likely when antigen levels are high or antigen exposure is prolonged. ${ }^{6}$ Lymphocyte exhaustion manifests initially with decreased IL-2 secretion; however, subsequently, other cytokines, including tumor necrosis factor $\alpha(\mathrm{TNF} \alpha)$, are secreted in lower amounts. ${ }^{7,8}$ Moreover, T-cell exhaustion impairs antigen-stimulated lymphocyte proliferation, halts lymphocyte renewal (mediated by IL-7 and IL-15), causes abnormal expression and function of transcription factors, decreases cytokine production, and impairs the response of memory T cells. ${ }^{9,10}$ In particular, an accumulation of exhausted cells is observed in the tumor microenvironment, which resembles the microenvironment of chronic inflammation. ${ }^{11}$ Functionally exhausted $\mathrm{T}$ cells have an increased expression of inhibitory molecules. ${ }^{12} \mathrm{~A}$ high expression of inhibitory receptors impairs the effector and proliferative functions of immune cells, and it creates a state of immunosuppression. Thus, the immune response toward cancer cells is insufficient and causes therapeutic failure. ${ }^{13}$

$\mathrm{T}$-cell anergy - that is, tolerance of $\mathrm{T}$ cells toward specific antigens - may develop due to TCR stimulation without sufficient co-stimulatory signals or in the presence of inhibitory stimulation. This mechanism of T-cell activation is associated with reduced IL-2 production and a state of hyporesponsiveness of T cells. T-cell anergy may develop in patients with cancer because co-inhibitory signals prevail over co-stimulatory signals in the tumor microenvironment. For example, there is a greater expression of the inhibitory B7 family proteins over B7 stimulatory protein in the tumor microenvironment. ${ }^{14}$

The $\mathrm{CD} 3 \zeta$ chain is an intracellular element of the TCR complex. Phosphorylation of the $\mathrm{CD} 3 \zeta$ chain is crucial for antigen-specific T-cell activation, and downregulation of the $\mathrm{CD} 3 \zeta$ chain is associated with a reduced response of T cells. Notably, $\mathrm{CD} 3 \zeta$ downregulation is observed in many cancers, particularly in tumor-infiltrating cells. ${ }^{15}$ As the $\mathrm{CD} 3 \zeta$ chain is crucial for $\mathrm{T}$-cell activation, $\mathrm{CD} 3 \zeta$ chain downregulation may be associated with T-cell exhaustion and T-cell apoptosis. ${ }^{16}$ Moreover, there is evidence that T-cell activation without CD3 $\zeta$ phosphorylation causes T-cell anergy. ${ }^{17}$

Finally, inhibitory signaling - due to overexpression of inhibitory molecules in the tumor microenvironment - is important in the development of T-cell dysfunction in cancer. Below, we describe the most important inhibitory molecules implicated in immune evasion by cancer cells (Table 1).

\section{Inhibitory molecules related to T-cell dysfunction in cancer PD-I}

PD-1 mRNA was first detected in the mouse thymus; after treatment with an anti-CD3 antibody, the thymocytes entering the path of the cell's programmed death showed an increase in PD-1 expression. ${ }^{18}$ Despite its name, PD-1 does not cause cell death, but it blocks the cell cycle. ${ }^{19,20} \mathrm{PD}-1$ is a transmembrane glycoprotein from the CD28:B7 family. It is mostly expressed on activated $\mathrm{T}$ and $\mathrm{B}$ cells, but is also expressed on activated monocytes, dendritic cells (DCs), and NK (natural killer) and NKT (natural killer T) cells. ${ }^{7}$ Unlike other molecules from the CD28 superfamily, which are expressed only by T cells, PD-1 is expressed by many cell types. This suggests that PD-1 has a central place in the regulation of immune responses. ${ }^{21} \mathrm{PD}-1$ is a receptor with a length of 288 amino acids, and it is encoded by the $P D C D-1$ gene on chromosome 2. PD-1 has an intracellular transmembrane domain and an extracellular immunoglobulin domain, which contains $21 \%-33 \%$ sequences that are identical to the sequences of cytotoxic T-lymphocyte-associated protein 4 (CTLA-4), CD28, and the inducible T-cell co-stimulator (ICOS). ${ }^{22}$ The receptor functions of PD-1 are mediated by its cytoplasmic part, which contains two tyrosine motifs that bind phosphatases responsible for transmitting immunosuppressive signals. The two motifs include the immunoreceptor tyrosine-based inhibitory motif(ITIM), located proximally to the cell membrane, and the immunoreceptor tyrosine-based switch motif (ITSM), which is essential to the inhibitory function of PD-1 (Figure 1). ${ }^{23} \mathrm{PD}-1$ expression is induced by the signaling pathways of the TCR and the B-cell receptor (BCR), and it is maintained during antigen stimulation. Moreover, some cytokines (IL-2, IL-7, and IL-15), Toll-like receptors (TLRs; TLR-9), and interferons (IFNs) stimulate the expression of PD-1 in T cells..$^{24,25}$ Moreover, the nuclear factor of activated $\mathrm{T}$ cells $\mathrm{c} 1$ (NFATc1) is important for PD-1 expression. ${ }^{26}$

\section{PD-LI and PD-L2}

Two PD-1 ligands that induce its inhibitory proprieties have been identified: PD-L1 (CD274 or B7-H1) and PD-L2 (CD273 or B7-DC). Both these ligands are type I transmembrane glycoproteins. ${ }^{27}$ The constitutive expression of PD-L1 
Table I Immune-checkpoint molecules and their inhibitors

\begin{tabular}{|c|c|c|c|c|}
\hline $\begin{array}{l}\text { Checkpoint } \\
\text { molecules }\end{array}$ & $\begin{array}{l}\text { Cellular } \\
\text { expression }\end{array}$ & $\begin{array}{l}\text { Main } \\
\text { ligands }\end{array}$ & Mechanism of action & Inhibitors \\
\hline CTLA-4 & $\begin{array}{l}\mathrm{CD}^{+} \mathrm{T} \text { cells } \\
\mathrm{CD} 8^{+} \mathrm{T} \text { cells, } \\
\text { Tregs }\end{array}$ & $\begin{array}{l}\text { CD80, } \\
\text { CD86 }\end{array}$ & $\begin{array}{l}\text { Competes with CD28 in binding to } \\
\text { CD80 and CD86 } \\
\text { Removes CD80 and CD86 from } \\
\text { APC surface } \\
\text { Treg-mediated immunosuppression } \\
\text { Induces T-cell anergy }\end{array}$ & $\begin{array}{l}\text { Ipilimumab - approved for advanced melanoma as } \\
\text { monotherapy or combined with nivolumab } \\
\text { Tremelimumab - investigated in melanoma, } \\
\text { mesothelioma, and NSLC but not approved due to a } \\
\text { lack of significant effect }\end{array}$ \\
\hline PD-I & $\begin{array}{l}\text { Activated T cells, } \\
\text { B cells, } \\
\text { APCs, } \\
\text { NK cells }\end{array}$ & $\begin{array}{l}\text { PD-LI, } \\
\text { PD-L2 }\end{array}$ & $\begin{array}{l}\text { Inhibits T-cell proliferation, } \\
\text { survival, and effector } \\
\text { function through } \mathrm{CD} 3 \zeta \text { chain } \\
\text { dephosphorylation } \\
\text { Decreases expression of survival } \\
\text { molecules }\end{array}$ & $\begin{array}{l}\text { Nivolumab - approved for advanced melanoma } \\
\text { as monotherapy or in combination with ipilimumab; } \\
\text { approved as monotherapy in lung cancer, renal cancer, } \\
\text { Hodgkin's lymphoma, urothelial cancer, head and neck } \\
\text { cancer, colorectal cancer, and hepatocellular carcinoma } \\
\text { Pembrolizumab - approved as monotherapy for } \\
\text { advanced melanoma, lung cancer (first-line treatment in } \\
\text { tumors with a high PD-LI expression, after chemotherapy } \\
\text { in tumors with a low PD-LI expression), Hodgkin's } \\
\text { lymphoma, large B-cell lymphoma, urothelial head and } \\
\text { neck cancer, gastric cancer, cervical cancer, breast cancer }\end{array}$ \\
\hline PD-LI & $\begin{array}{l}\text { T cells, } \\
\text { B cells, } \\
\text { DCs, } \\
\text { MSCs, } \\
\text { cancer cells }\end{array}$ & PD-I & Same as in PD-I & $\begin{array}{l}\text { Atezolizumab - approved as monotherapy for } \\
\text { advanced urothelial carcinoma, lung cancer, colorectal } \\
\text { cancer, breast cancer, renal cancer } \\
\text { Avelumab - approved as monotherapy for metastatic } \\
\text { Merkel cell carcinoma } \\
\text { Darvulumab - approved as monotherapy for urothelial } \\
\text { cancer }\end{array}$ \\
\hline LAG-3 & $\begin{array}{l}\text { Activated T cells, } \\
\text { NK cells }\end{array}$ & $\begin{array}{l}\text { MHC } \\
\text { class II }\end{array}$ & $\begin{array}{l}\text { Inhibits } \mathrm{CD} 4^{+} \text {cell function } \\
\text { Directly inhibits cytotoxic function } \\
\text { of } C D 8^{+} \text {cells }\end{array}$ & $\begin{array}{l}\text { LAG-3-Ig fusion protein and anti-LAG-3 mAbs - } \\
\text { investigated in renal cancer, breast cancer, and pancreatic } \\
\text { cancer as monotherapy or combined with other therapies }\end{array}$ \\
\hline TIM-3 & $\begin{array}{l}\text { CD4 } 4^{+} \text {cells, } \\
\text { Th } 17 \text { cells, } \\
\text { CD8 } 8^{+} \text {cells } \\
\text { NK cells }\end{array}$ & Gal-9 & $\begin{array}{l}\text { Decreases interferon- } \gamma \text { production } \\
\text { Induces T-cell apoptosis } \\
\text { Promotes generation of MDSCs }\end{array}$ & $\begin{array}{l}\text { Different anti-TIM-3 mAbs - investigated in many } \\
\text { solid tumors and leukemia }\end{array}$ \\
\hline
\end{tabular}

Abbreviations: APCs, antigen-presenting cells; DCs, dendritic cells; CTLA-4, cytotoxic T-lymphocyte-associated antigen 4; LAG-3, lymphocyte-activation gene 3; mAbs, monoclonal antibodies; MHC, major histocompatibility complex; MDSCs, myeloid-derived stem cells; MSCs, mesenchymal stem cells; NK, natural killer; PD-I, programmed cell death protein I; PD-LI, programmed death-ligand I; TIM-3, T-cell immunoglobulin and mucin domain 3; Tregs, T-regulatory cells.

is substantially higher in mice than in humans, particularly in T and B cells, DCs, macrophages, and mesenchymal stem cells (MSCs); moreover, PD-L1 expression increases during activation of these cells. ${ }^{28,29}$ Besides hematopoietic cells, PD-L1 is expressed by other cell types, such as pancreatic cells, epithelial cells, endothelial cells, muscle cells, hepatocytes, astrocytes, spleen cells, kidney cells, and lung cells. ${ }^{28-31}$ PD-L2 is expressed only in the core layer of the thymus and, in lesser amounts, in the fetal myocardium and endothelial cells - particularly within the placenta. ${ }^{32,33}$ PD-L2 expression can be induced on DCs, peritoneal B1 lymphocytes, macrophages, medullary mast cells, and memory B cells. ${ }^{34}$ Importantly, PD-L1 and PD-L2 are expressed by cancer cells, cancer-associated fibroblasts, and myeloid-derived stem cells. The expression of PD-L2 increases only slightly on stimulated $\mathrm{CD} 8^{+} \mathrm{T}$ cells, but it does not increase at all on
CD4 ${ }^{+}$lymphocytes..$^{35}$ Binding of PD-1 to PD-L1 or PD-L2 during TCR activation suppresses the proliferation of both $\mathrm{B}$ and $\mathrm{T}$ cells, decreases cytokine secretion, inhibits cytolysis, and prolongs T-cell survival. ${ }^{36}$ PD-L1- or PD-L2-mediated prolongation of T-cell survival and impairment of their function may occur both indirectly, through interference with the early activating signals induced by CD28, and directly, through interference with IL-2 secretion. ${ }^{37}$ Furthermore, PD-L1 is essential for Treg induction by DCs. ${ }^{38}$

\section{CTLA-4}

CTLA-4 is a transmembrane receptor protein that inhibits T-cell function, mostly by competing with the co-stimulatory molecule $\mathrm{CD} 28$ for $\mathrm{CD} 80$ and CD86 located on antigenpresenting cells (APCs). CTLA-4 is expressed on conventional $\mathrm{CD}^{+}$and $\mathrm{CD} 8^{+} \mathrm{T}$ cells after TCR stimulation, 
APC/tumor cell

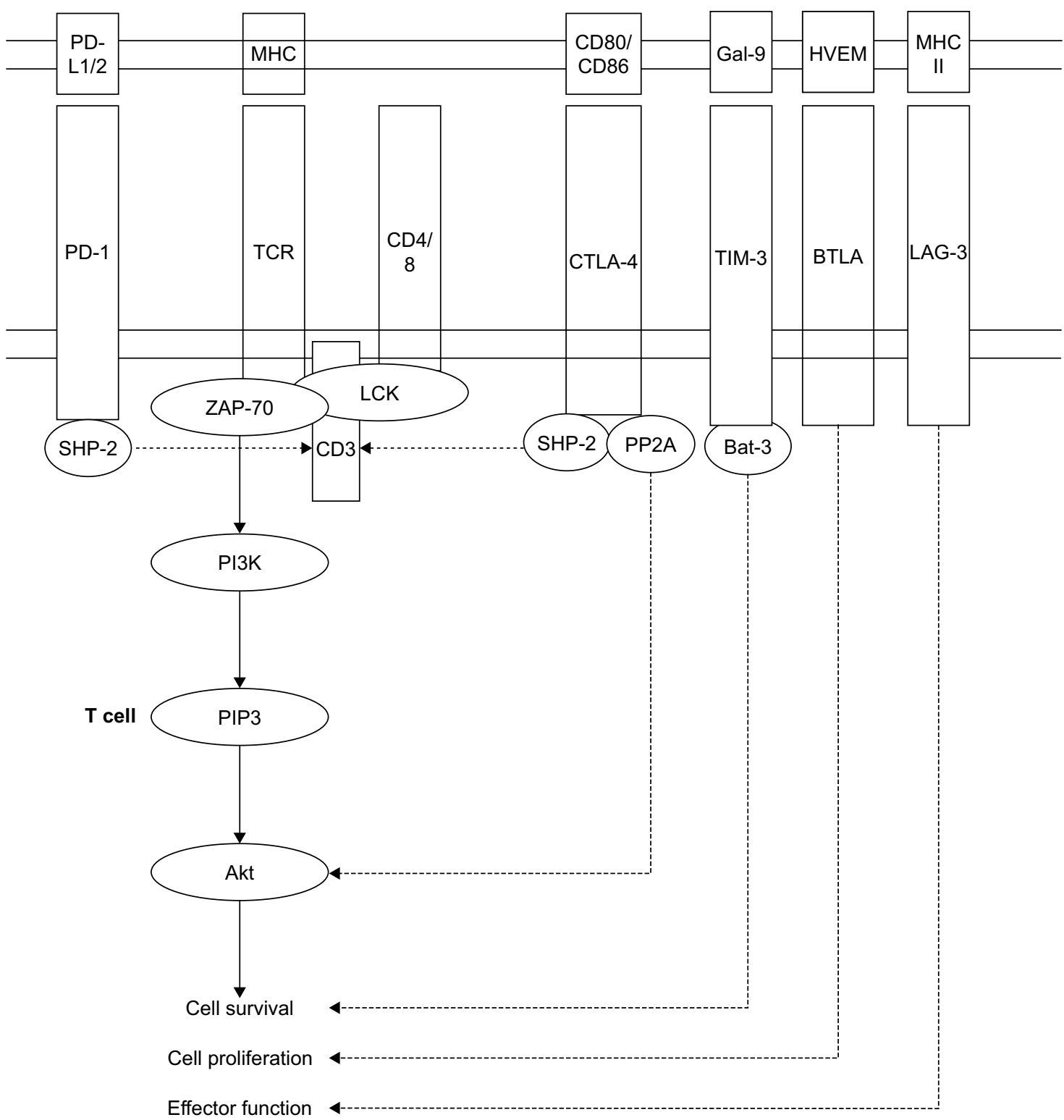

Stimulation

Inhibition

Figure I Signaling pathways of immune-checkpoint molecules.

Notes: Binding of PD-LI/L2 to PD-I recruits SHP-2, which inhibits TCR signaling by CD3 3 -chain dephosphorylation. Thus, the signaling cascade leading to T-cell survival, proliferation, and effector function is inhibited. The SHP-2 recruitment is dependent on its ITSM, whereas the ITIM is not needed for this action. Binding of CTLA-4 to CD80/86, in addition to SHP-2 recruitment, engages PP2A, which directly dephosphorylates AKT. The signaling pathways of TIM-3, LAG-3, and BTLA are less known. Binding of TIM-3 to galectin-9 phosphorylates the Y265 intracellular TIM-3 domain. This disrupts the interaction between TIM-3 and Bat-3, which otherwise inactivates the inhibitory effects of TIM-3. The inhibitory effects due to the binding of MHC II to LAG-3 are dependent on the intracellular KIEELE domain of LAG-3. It is suspected that the intracellular ITIM domain of BTLA is necessary for its inhibitory effects after binding to HVEM.

Abbreviations: BTLA, B- and T-lymphocyte attenuator; CTLA-4, cytotoxic T-lymphocyte-associated antigen 4; HVEM, herpesvirus entry mediator; ITIM, immunoreceptor tyrosine-based inhibition motif; ITSM, immunoreceptor tyrosine-based inhibition motif; LAG-3, lymphocyte-activation gene 3; MHC, major histocompatibility complex; PI3K, phosphoinositide 3-kinase; PD-I, programmed cell death protein I; PD-LI, programmed death-ligand I; PD-L2, programmed death-ligand 2; PIP3, phosphatidylinositol (3,4,5)trisphosphat; PP2A, protein phosphatase 2A; TCR, T-cell receptor; TIM-3, T-cell immunoglobulin and mucin domain 3.

which prevents an excessive early immune reaction; moreover, CTLA-4 is essential for the suppressive function of regulatory T cells (Treg). ${ }^{39,40}$ CTLA-4 ligation causes lymphocyte anergy, which reduces the synthesis of IFN $\gamma$, IL-2, IL-3, and granulocyte-macrophage colony-stimulating factor (GM-CSF), and increases the production of transforming growth factor beta (TGF $\beta$ ). ${ }^{41}$ The synthesis of CTLA-4 mRNA increases within the first hours of lymphocyte stimulation, and peaks after $48-72$ hours. ${ }^{42}$ CTLA-4 stimulation makes lymphocytes more likely to remain in the $\mathrm{G}_{0} / \mathrm{G}_{1}$ 
phase of the cell cycle, which is due to a reduced synthesis of cyclin D3 and kinases cdk4/cdk6, degradation of the inhibitory protein $\mathrm{p} 27$, and increased expression of cyclin D2. ${ }^{43}$ Anergic lymphocytes are not activated after antigen recognition even when they receive co-stimulatory signals sufficient to activate a naïve lymphocyte. CD86, like CD80, is a ligand for CD28 and CTLA-4, and it is important in the co-stimulation of T cells during the primary immune response. CD86 belongs to the superfamily of immunoglobulins, and it is expressed on monocytes, DCs, as well as activated T, $\mathrm{B}$, and NK cells. The chromosome region encoding CD86 contains a series of genes involved in carcinogenesis. ${ }^{44,45}$ Blocking CTLA-4 by monoclonal antibodies (mAbs) maintains $T$ cells in an activation state and improves the immune response against cancer cells. Thus, anti-CTLA-4 mAbs are effective in cancer immunotherapy.

\section{LAG-3}

LAG-3 (CD223) prevents an excessive immune activation. This receptor is expressed by $\mathrm{T}$ and NK cells after MHC class II ligation, and by cytotoxic $\mathrm{T}$ cells upon antigen stimulation. ${ }^{22,46}$ LAG-3 inhibits $\mathrm{CD}^{+}$cell activation and directly decreases the cytotoxic function of $\mathrm{CD}^{+}$cells. ${ }^{46,47}$ Blocking LAG-3 restores the function of cytotoxic T cells and simultaneously inhibits Tregs. ${ }^{48}$ Preclinical studies showed that LAG-3, fused with immunoglobulin (LAG3-Ig), binds with a high affinity to MHC II of DCs, which stimulates DC maturation, and that, in turn, potentiates $\mathrm{T}$ helper 1 (Th1)-type responses. ${ }^{49}$ In contrast, monomeric LAG-3, shed from the cell surface, does not bind to MHC class II molecules. ${ }^{46}$

\section{TIM-3}

Expression of the type I transmembrane protein TIM-3 was shown in many immune cell types, including Th1, Th17, NK, and NKT cells as well as Tregs; on APCs, TIM-3 is co-expressed with PD-1. ${ }^{50}$ TIM-3 binds to galectin-9, which causes apoptosis of $\mathrm{CD}^{+}$and $\mathrm{CD}^{+}$cells through the calcium-calpain-caspase-1 pathway. ${ }^{51,52}$ Galectin-9 is expressed on the surface of many cancer cell types, whereas the expression of TIM-3 was observed in tumor-infiltrating T cells in mice. TIM-3 directly inhibits Th1-mediated autoimmunity, and it indirectly promotes immunosuppression by inducing expansion of myeloid-derived suppressor cells (MDSCs), through an unknown mechanism. ${ }^{22,53}$ Blocking TIM-3 increases the production of IFN $\gamma$ by lymphocytes, but it is unclear as to what forms the molecular basis of this action. ${ }^{54}$ In patients with gastric, colorectal, liver, and pancreatic cancers, TIM-3 tumor expression correlated with tumor invasion, reduced survival, and metastasis; thus, TIM-3 can be implicated in carcinogenesis. ${ }^{55}$

\section{B- and T-lymphocyte attenuator (BTLA)}

BTLA is a glycoprotein containing an immunoglobulin domain, and it is expressed on T cells, resting B cells, macrophages, DCs, and NK cells. ${ }^{56}$ BTLA downregulates the activity of lymphocytes after binding to its ligand - the herpesvirus entry mediator (HVEM) molecule. HVEM belongs to the TNF receptor superfamily, whereas BTLA and CD160 are members of the immunoglobulin superfamily. ${ }^{57}$ The functions and structures of these co-stimulatory molecules are related to positive and negative co-stimulatory pathways. ${ }^{57,58}$ Binding of BTLA to HVEM inhibits the proliferation of $\mathrm{CD}^{+} \mathrm{T}$ cells, production of proinflammatory cytokines, and formation of memory $\mathrm{T}$ cells; at the same time, it promotes peripheral tolerance. ${ }^{59}$ Studies in the $\mathrm{HVEM}^{-/-}$knockout $^{-}$ mouse have shown, however, that immunosuppressive function is preserved in this animal model. ${ }^{60}$

\section{Novel immune-checkpoint molecules}

Novel immune-checkpoint molecules that could be future targets for cancer treatments are being investigated. They include, for example, HHLA2, TMIGD2, B7x, B7 homologue 3 (B7-H3), T-cell immunoglobulin and ITIM domain (TIGIT), CD96, 2B4, and adenosine A2a receptor (A2aR). ${ }^{22,61}$ Moreover, blockade of the V-domain Ig Suppressor of T cell Activation (VISTA) protein is a promising add-on therapy to PD-1 inhibitors because it inhibits T-cell activation via different pathways than does PD- $1 .^{62}$ In addition to immunecheckpoint inhibition, enhancement of immune-stimulatory pathways (OX40, GITR, and CD40) is considered in cancer treatment. Future studies will show which new molecule will be used to treat cancer along the currently approved CTLA-4 and PHD-1 inhibitors. In our opinion, because of an advanced program of clinical trials, LAG-3 will be the third approved target for immune-checkpoint inhibition. ${ }^{46}$

\section{Blockade of T-cell dysfunction as a new method of cancer immunotherapy}

TCR-mediated antigen recognition is the most important signal for $\mathrm{T}$-cell activation. In addition, there are costimulatory and co-inhibitory molecules on the surface of effector $\mathrm{T}$ cells that take part in the immune response against tumor cells. Ligands for these molecules are found on the surface of APCs and tumor cells (Figure 1). ${ }^{63}$ The interaction between specific cell-surface molecules and their ligands directs lymphocyte response. PD-L1 and 
PD-L2, both located on the surface of APCs and tumor cells, inhibit lymphocyte activity by binding to PD-1 on the lymphocyte surface. ${ }^{64}$ The interaction between CD28 on the T-cell surface and CD80 (B7/B7.1) and CD86 (B70/ B7-2) on the surface of APCs or tumor cells is crucial for the activation of effector $\mathrm{T}$ cells. However, when CD80 and CD86 bind to the cytotoxic T-cell antigen 4 (CTLA-4) instead of CD28, lymphocyte anergy and apoptosis occur. ${ }^{65}$ In the tumor microenvironment, wherein signals that inhibit effector $\mathrm{T}$ cells predominate, tumor cells may avoid immune response. ${ }^{66}$ Because mAbs against the molecules implicated in T-cell dysfunction may boost the immune response in the tumor microenvironment, these antibodies have a therapeutic potential in certain cancers. Currently, mAbs against the PD-1/PD-L1 pathway, CTLA-4, lymphocyte activation gene 3 (LAG-3), T-cell immunoglobulin and mucin domain 3 (TIM-3), and BTLA are either an approved treatment or are undergoing phase III clinical trials in patients with different cancers; some of these treatments are investigated in preclinical studies ${ }^{63}$ Table 2 presents a list of completed clinical trials of immune-checkpoint inhibitors in patients with cancer. ${ }^{67}$

\section{Blockade of PD-I and its ligands}

PD-1 and PD-L1 are expressed both on tumor cells and on tumor-specific immune cells. ${ }^{22,23,29}$ In humans, PD-L1 is expressed by different tumors, and it is a negative prognostic factor in some of them. In cervical cancer, however, PD-L1 expression was associated with a longer overall survival. ${ }^{68}$ The expression of PD-L1 on tumor cells may be associated with a decreased number of tumor-infiltrating lymphocytes. ${ }^{69}$ PD-L2 is expressed by colorectal cancer, non-small-cell lung cancer, head and neck squamous cell carcinoma, hepatocellular carcinoma, cervical cancer, and some B-cell leukemias. ${ }^{70}$ Moreover, PD-1 and its ligands are expressed by immune cells in the tumor microenvironment. In breast cancer, Hodgkin's lymphoma, and head and neck cancer, PD-1 expression by tumor-infiltrating lymphocytes correlated with tumor size and a lower overall survival. ${ }^{71}$ Further, increased PD-1 expression was observed on DCs in the tumor microenvironment, which reduced the DC-mediated activation of T cells. ${ }^{72}$ PD-L1 expression on tumor cells is induced mainly by IFN $\gamma$, which is produced by tumorinfiltrating lymphocytes. ${ }^{73}$ Thus, tumor cells can protect themselves from lymphocytes by expressing PD-L1, which inhibits lymphocyte activation and considerably reduces their efficacy. ${ }^{74}$ Tumor-associated DCs expressing PD-L1 produce suppressive IL-10. ${ }^{75}$ In animal studies, the PD-1:PD-L1 interaction enables Treg-mediated suppression of $\mathrm{CD} 8^{+}$ $\mathrm{T}$ cells in the tumor microenvironment. ${ }^{76}$ Blockade of the PD-1:PD-L1/2 pathway may increase the therapeutic effectiveness in patients with cancer by reducing the exhaustion of effector $\mathrm{T}$ cells.

In 2002, the therapeutic effects of anti-PD-1 antibodies were first observed in mice with PD-L1-positive tumors. ${ }^{77}$ These and other preclinical findings encouraged phase I clinical trials in patients with cancer. ${ }^{66}$ In the first clinical trials of an anti-PD-1 mAb (MDX-1106, nivolumab), an objective response was observed in multiple cancer types, including melanoma, non-small-cell lung cancer, and renal cell cancer. ${ }^{78}$ The drug-related toxicity was acceptable, and the anticancer effect was long term. ${ }^{56}$ Nivolumab proved effective not only in immunogenic tumors like melanoma and renal cell cancer, but also in non-small-cell lung cancer (considered insensitive to immunotherapy), hepatocellular cancer, metastatic colorectal cancer, squamous cell carcinoma of the head and neck, and urothelial carcinoma. ${ }^{56,79,80}$ In addition, nivolumab was investigated in patients with hematological malignancies (Hodgkin's lymphoma) because PD-1 ligands are expressed in these cancers. ${ }^{81}$ Currently, nivolumab and nivolumab-combined therapies are approved by the US Food and Drug Administration (FDA) for the treatment of melanoma, lung cancer, advanced and metastatic renal cell carcinoma, Hodgkin's lymphoma, head and neck cancers, urothelial carcinoma, colorectal cancer, and hepatocellular carcinoma (Table 1). ${ }^{82}$

In phase I clinical trials, treatment with pembrolizumaban anti-PD-1 $\mathrm{mAb}$ - was associated with a favorable objective response and a high survival rate in patients with advanced melanoma. ${ }^{83}$ Further studies showed that pembrolizumab was effective in patients with advanced urothelial carcinoma, gastric cancer, non-small-cell lung cancer, and squamous cell carcinoma of the head and neck. ${ }^{56}$ Similarly to nivolumab, the effects of pembrolizumab are durable, and the frequency of third- or fourth-level adverse effects related to drug administration is relatively low. ${ }^{84}$ In a phase III clinical trial, in patients with advanced melanoma, pembrolizumab was associated with a higher survival rate and a higher percentage of objective responses as compared with ipilimumab - an anti-CTLA-4 mAb. ${ }^{85}$ Currently, pembrolizumab is approved for the treatment of advanced melanoma, advanced or metastatic non-small-cell lung cancer, recurrent or metastatic head and neck squamous cell carcinoma, Hodgkin's lymphoma, advanced or metastatic urothelial carcinoma, and recurrent locally advanced or metastatic gastric or gastroesophageal junction cancers. ${ }^{82}$ Treatment with another anti-PD-1 mAb- 


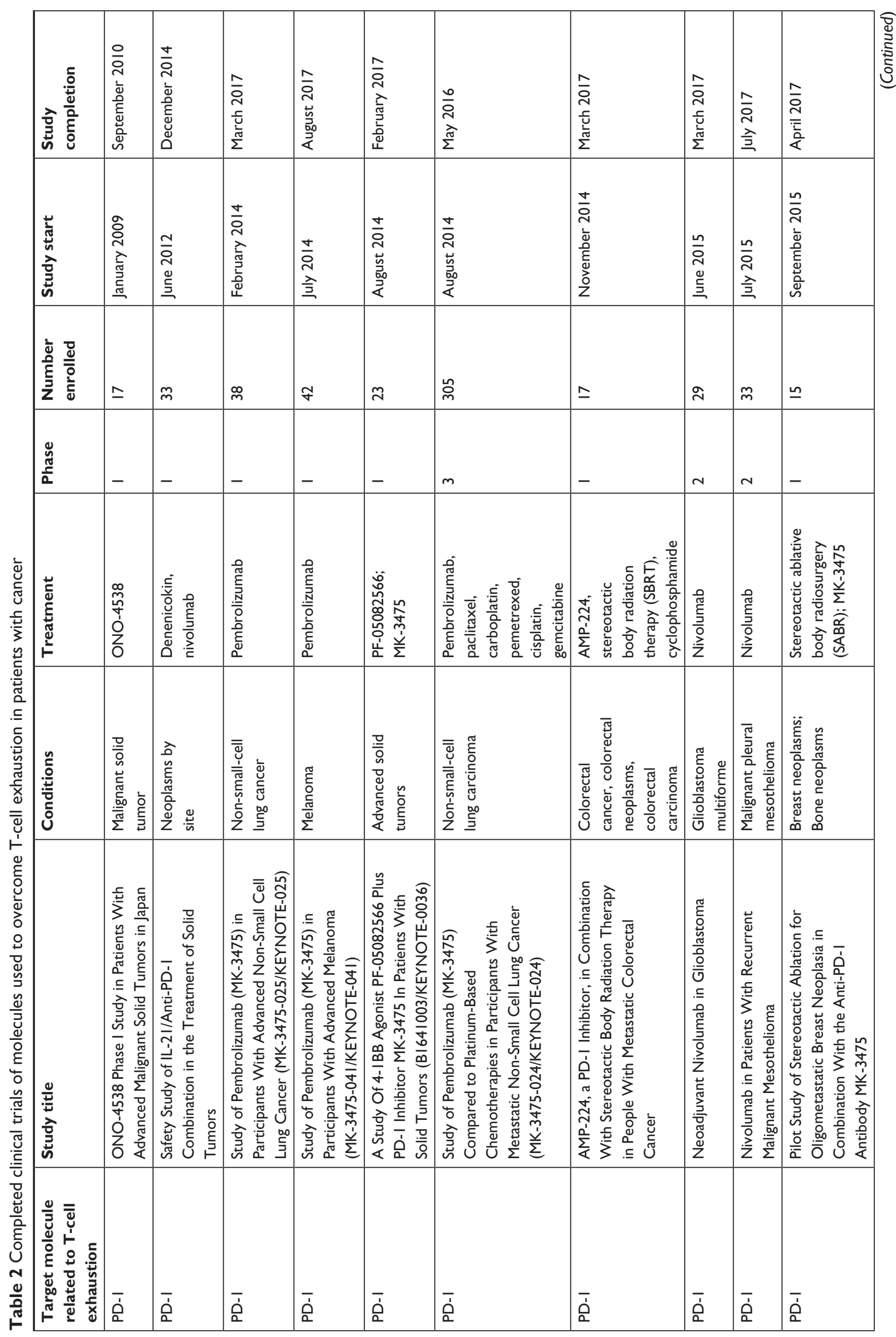




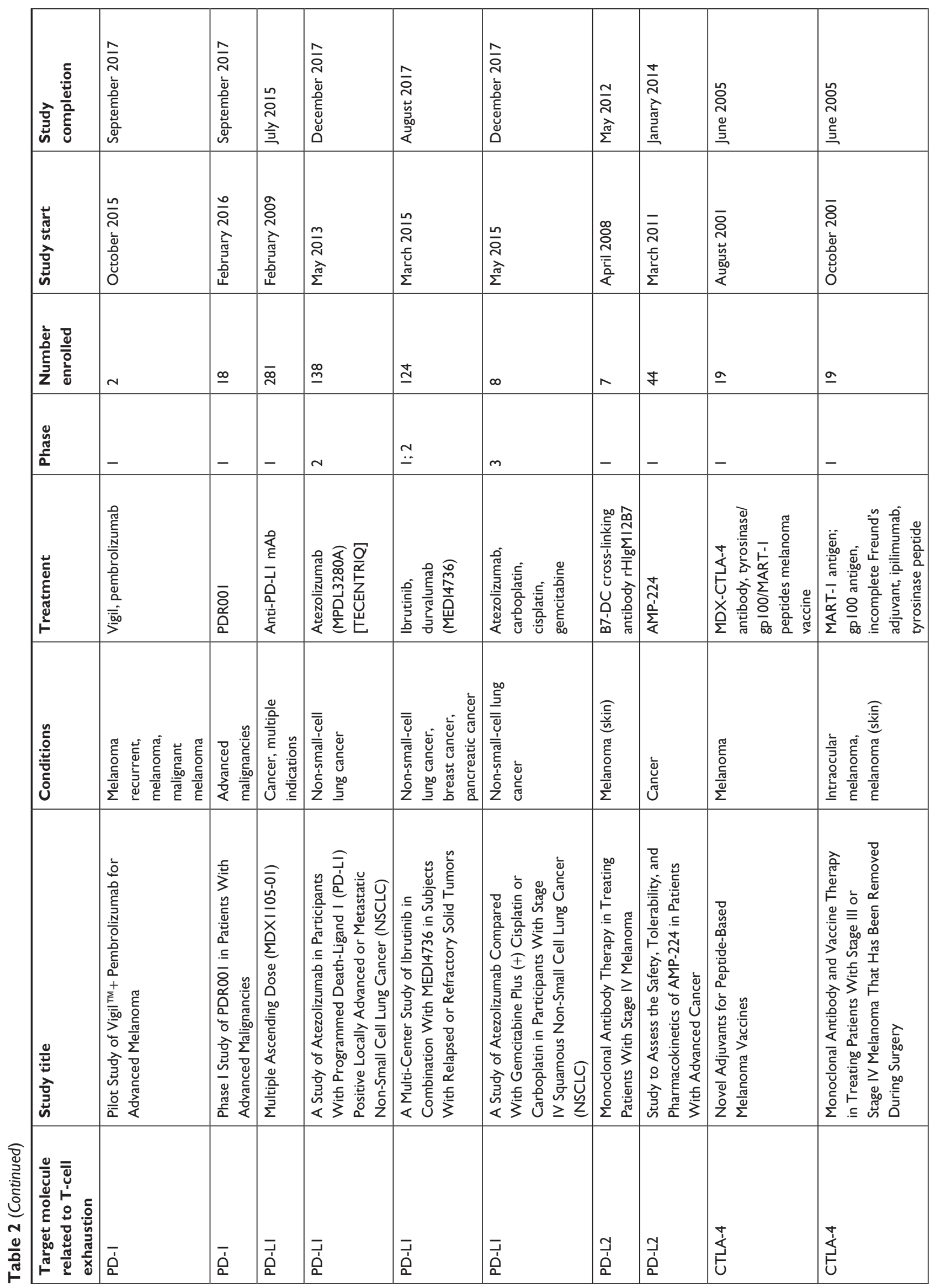




\begin{tabular}{|c|c|c|c|c|c|c|}
\hline 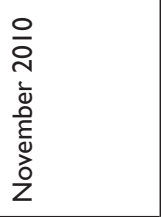 & 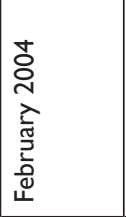 & 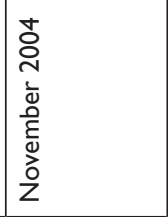 & 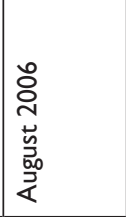 & 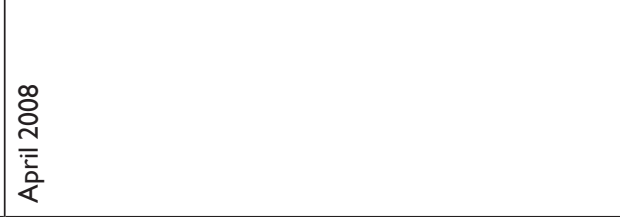 & 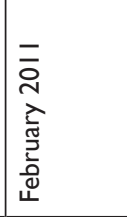 & 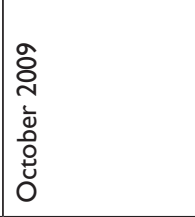 \\
\hline 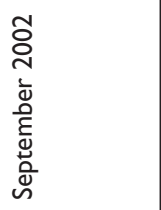 & 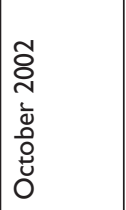 & 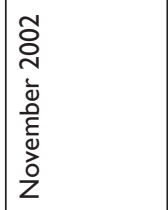 & 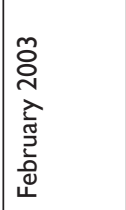 & 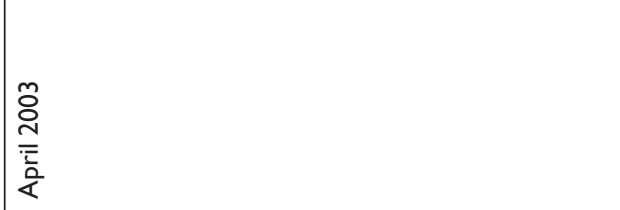 & 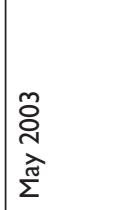 & 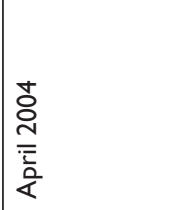 \\
\hline$\infty$ & 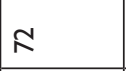 & q & mి & $\bar{N}$ & F & $\underline{\infty}$ \\
\hline- & $\sim$ & N & $\stackrel{\sim}{二}$ & - & - & - \\
\hline 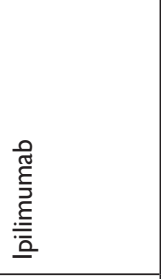 & 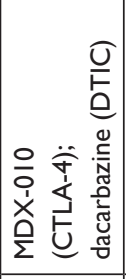 & 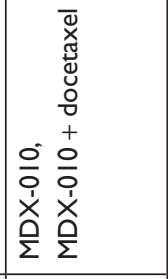 & 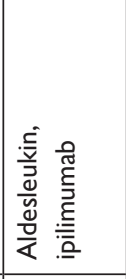 & 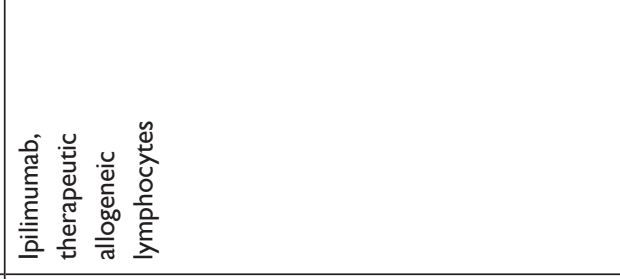 & 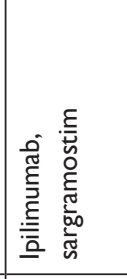 & 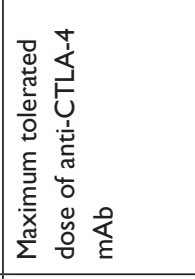 \\
\hline 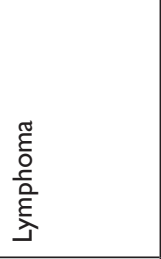 & 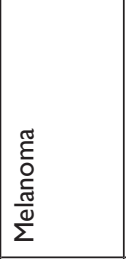 & 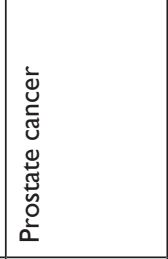 & 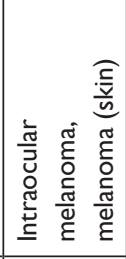 & 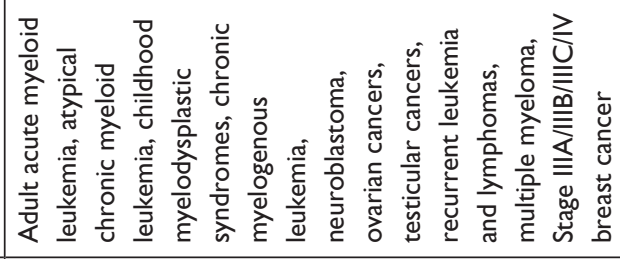 & 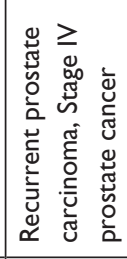 & 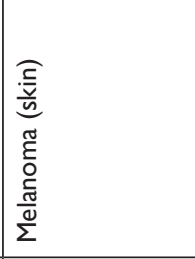 \\
\hline 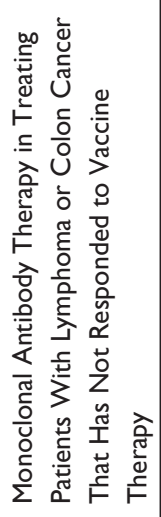 & 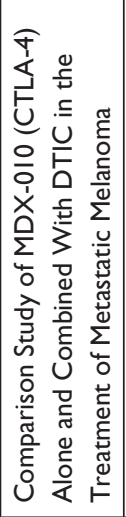 & 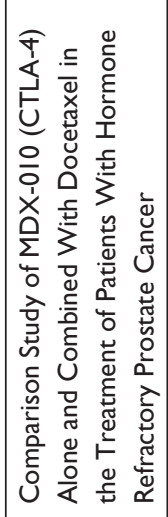 & 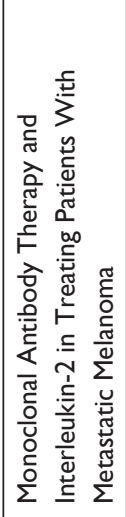 & 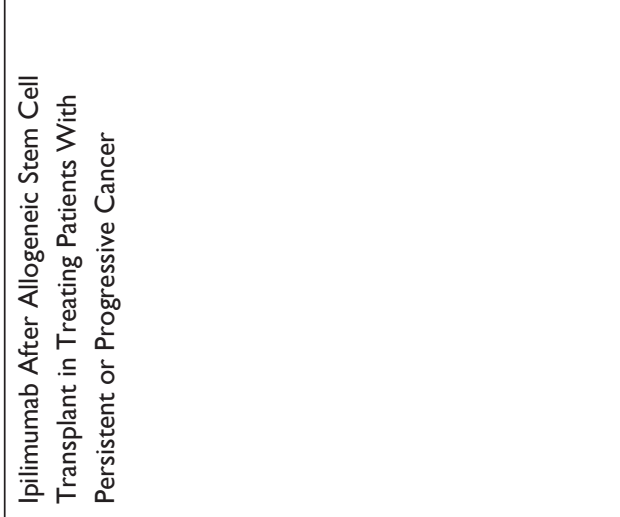 & 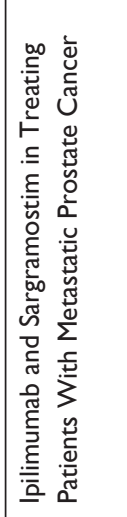 & 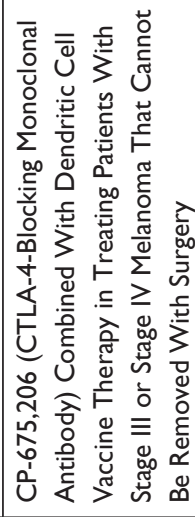 \\
\hline$\underset{\dot{U}}{\stackrel{+}{\dot{S}}}$ & 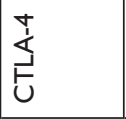 & $\sum_{\substack{+\\
}}^{+}$ & 荌 & 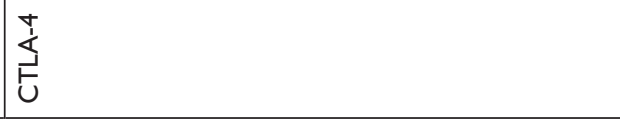 & $\underset{\dot{S}}{\stackrel{+}{\dot{S}}}$ & $\stackrel{+}{\stackrel{+}{S}}$ \\
\hline
\end{tabular}




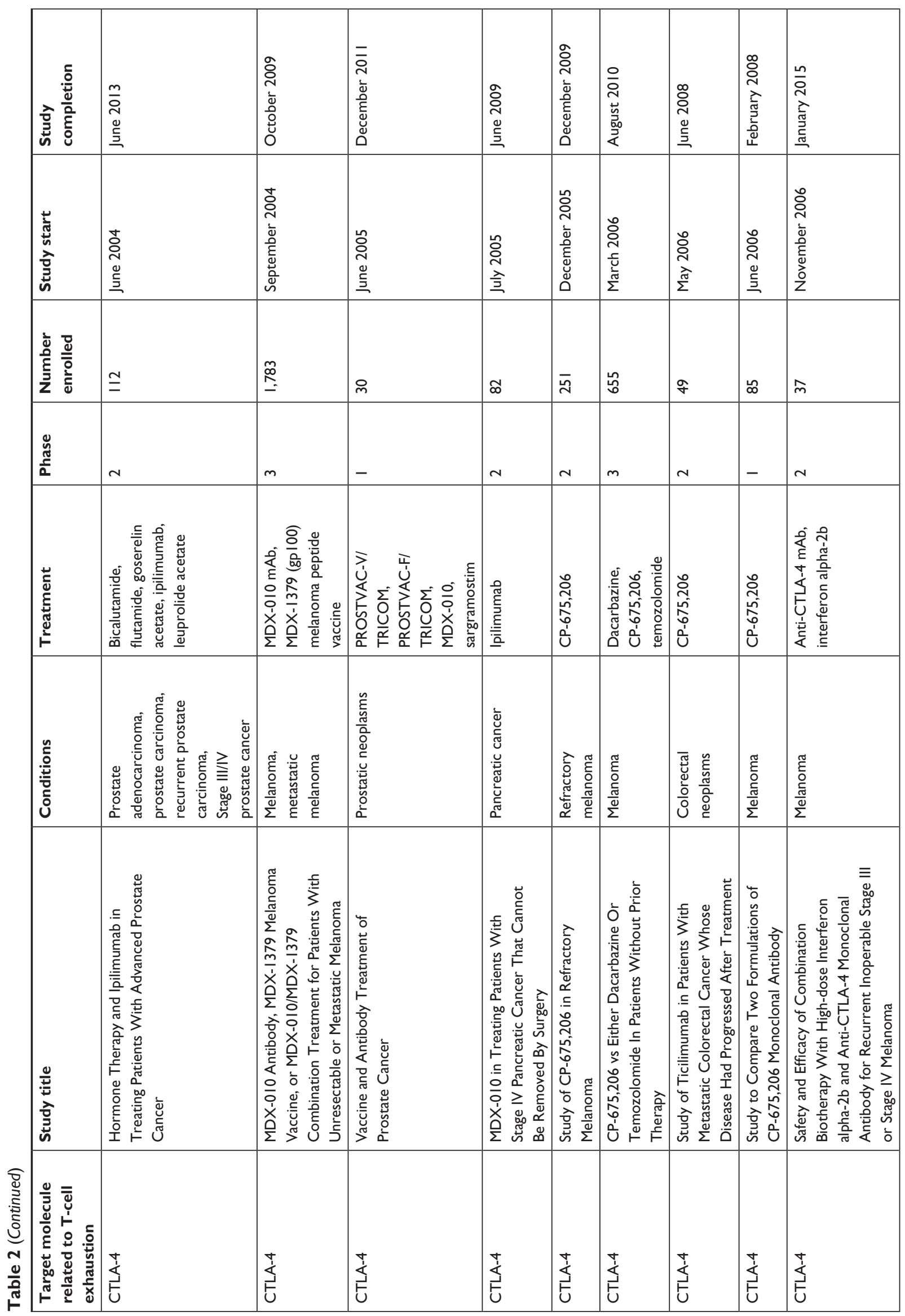




\begin{tabular}{|c|c|c|c|c|c|c|c|c|c|c|}
\hline 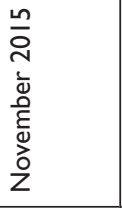 & 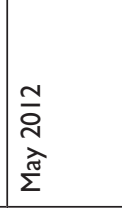 & $\begin{array}{l}\text { 竞 } \\
\text { 交 }\end{array}$ & 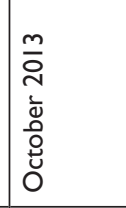 & 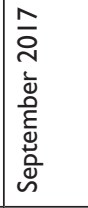 & 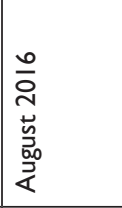 & 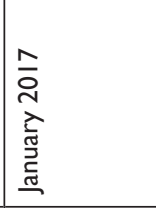 & 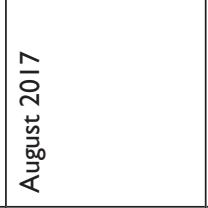 & 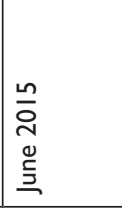 & 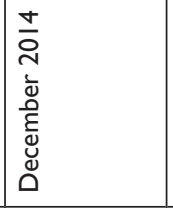 & 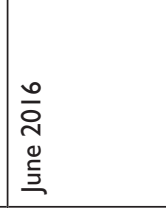 \\
\hline 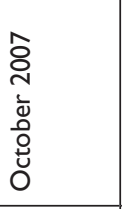 & 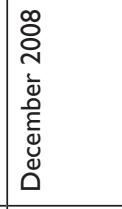 & 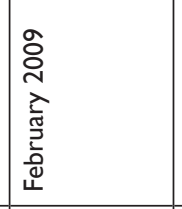 & 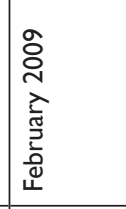 & 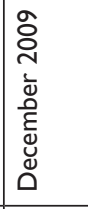 & 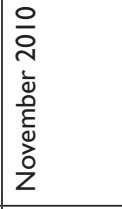 & 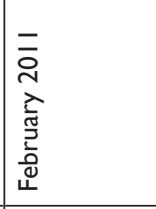 & 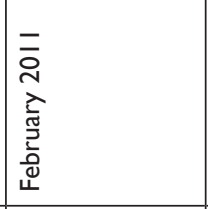 & $\begin{array}{l}\overline{\bar{i}} \\
\text { o. } \\
\underline{\underline{\underline{\Xi}}} \\
\end{array}$ & 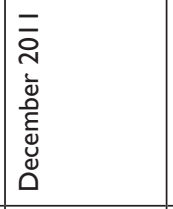 & 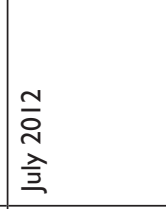 \\
\hline m & $i$ & $\stackrel{m}{m}$ & $\underline{\underline{1}}$ & in & $\stackrel{\omega}{\mu}$ & $\stackrel{\rho}{m}$ & $\underset{\sim}{2}$ & $f$ & $\stackrel{\sigma}{ }$ & Na \\
\hline- & a & - & $\stackrel{\sim}{\ddot{*}}$ & $\begin{array}{l}\text { 골 } \\
\end{array}$ & N & N & N & N & - & - \\
\hline 胥 & $\begin{array}{l}0 \\
0 \\
0 \\
0 \\
0 \\
0 \\
0 \\
0\end{array}$ & 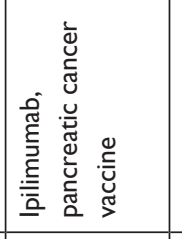 & 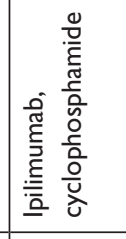 & 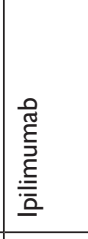 & 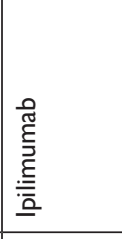 & 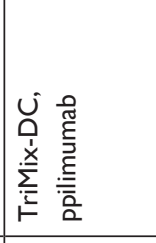 & 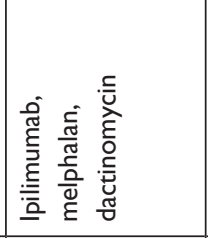 & 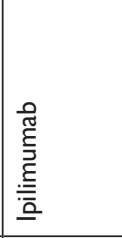 & 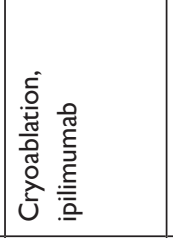 & 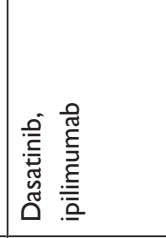 \\
\hline 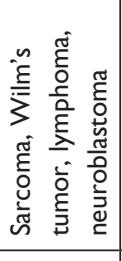 & 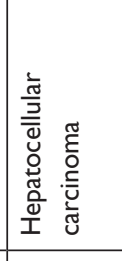 & 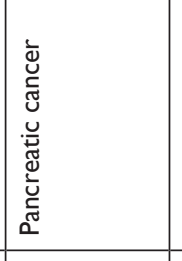 & 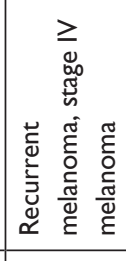 & 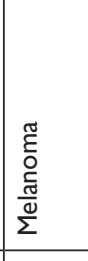 & 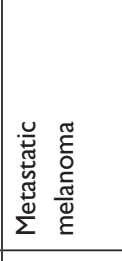 & 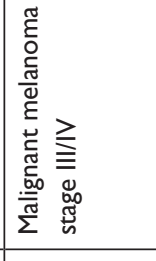 & 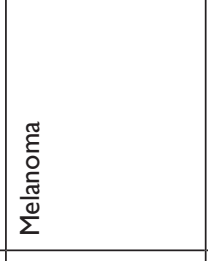 & 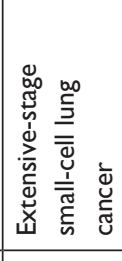 & 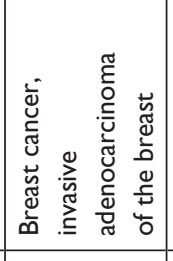 & 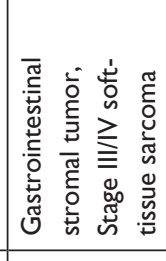 \\
\hline 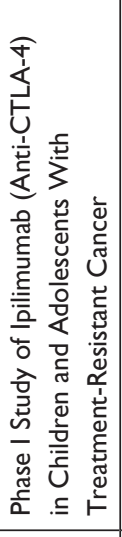 & 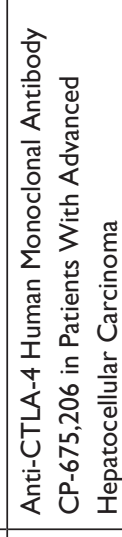 & 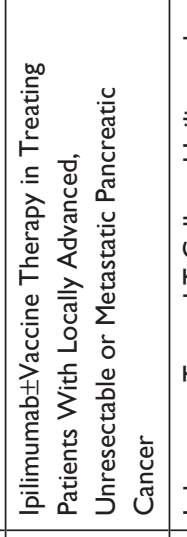 & 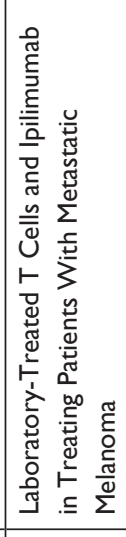 & 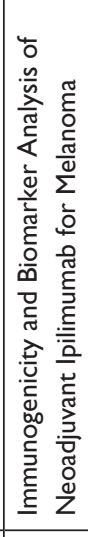 & 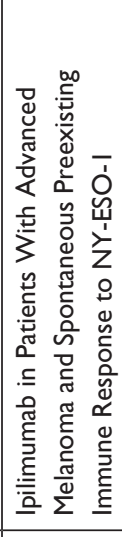 & 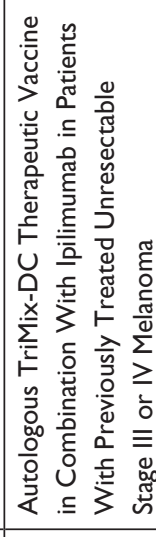 & 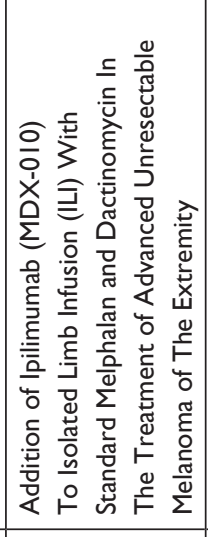 & 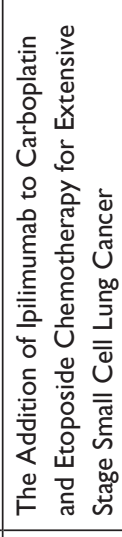 & 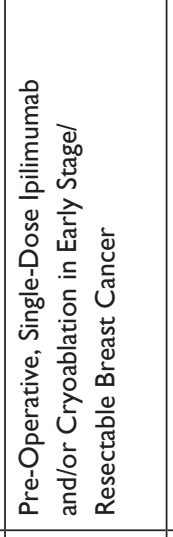 & 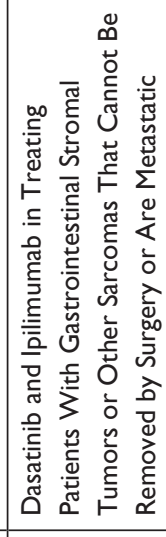 \\
\hline 范 & $\begin{array}{l}\dot{T} \\
\dot{U} \\
\dot{U}\end{array}$ & 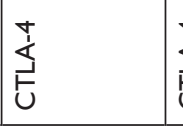 & 菅 & 密 & 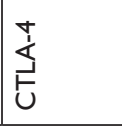 & S. & 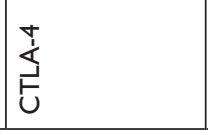 & 妾 & 先 & 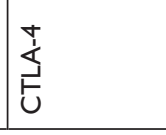 \\
\hline
\end{tabular}




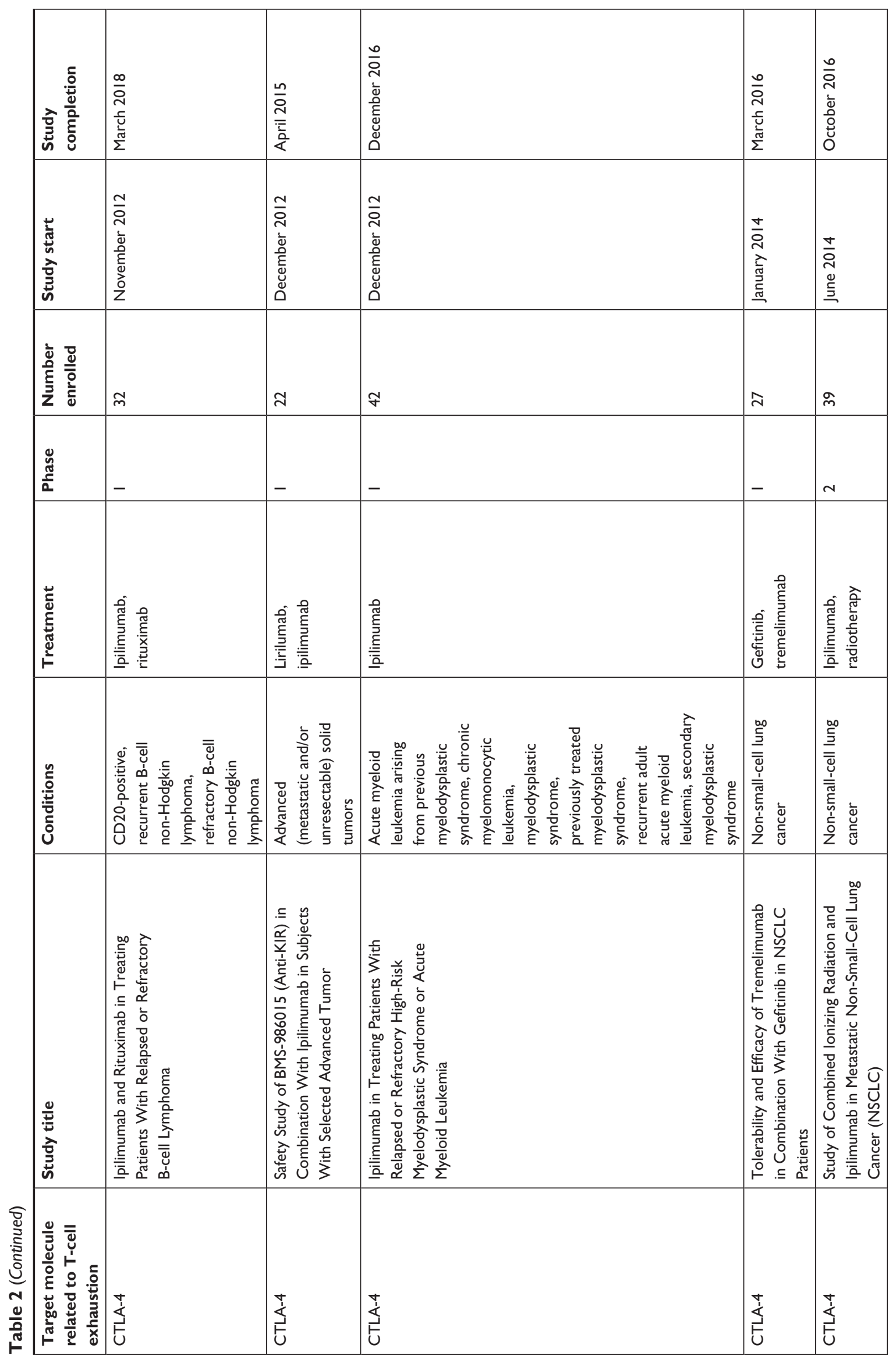




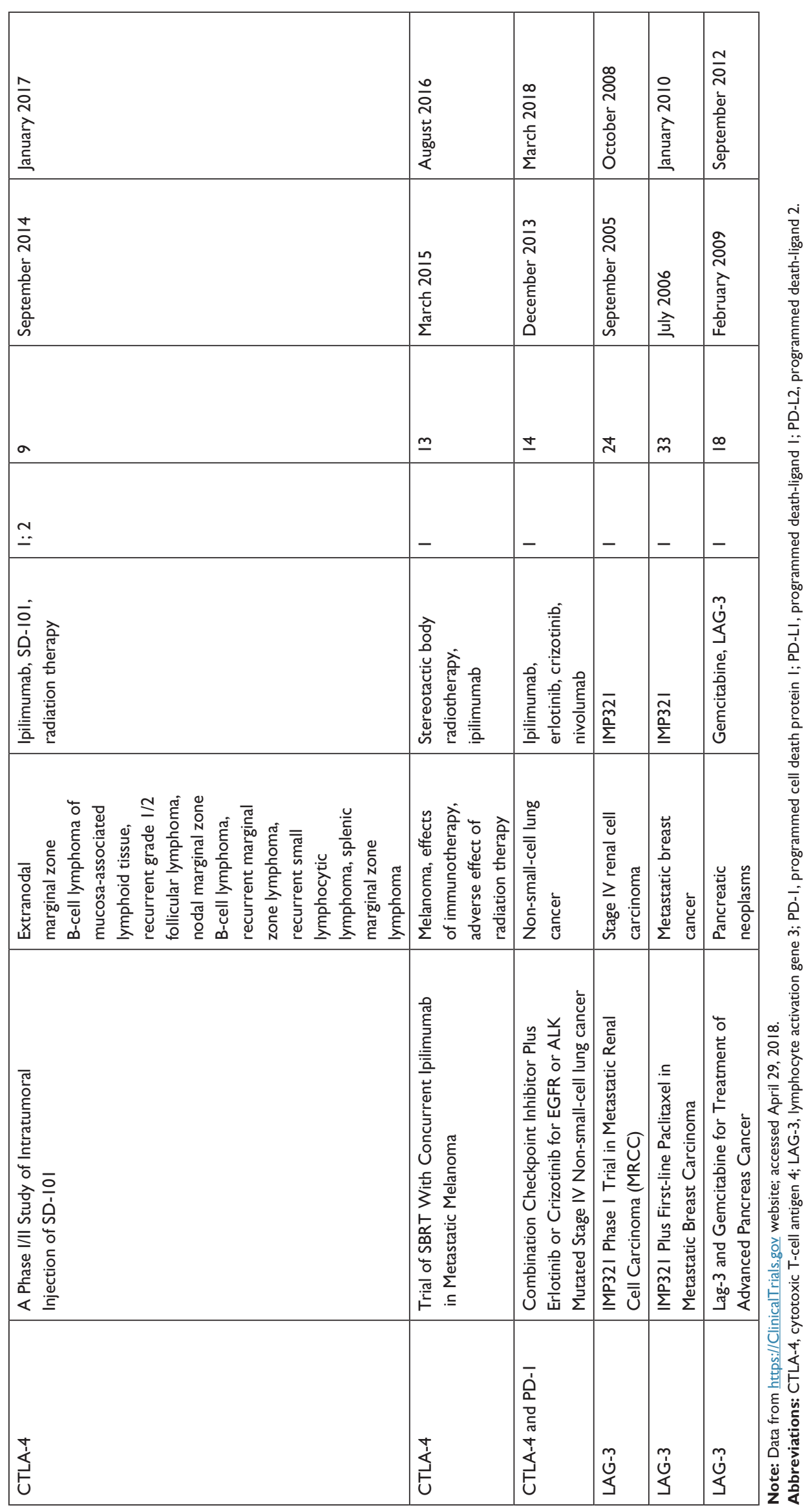


pidilizumab - showed an encouraging effect in patients with diffuse large B-cell lymphoma (DLBCL) after autologous hematopoietic stem-cell transplantation and with relapsed follicular lymphoma. ${ }^{86,87}$

The effects of anti-PD-L1 mAbs can differ from those of the anti-PD-1 mAbs because PD-L1 and PD-1 have different ligands. ${ }^{66}$ BMS-936559 - an anti-PD-L1 mAb caused an objective and durable response in patients with melanoma, lung cancer, kidney cancer, and ovarian cancer. ${ }^{88}$ MPDL3280A (atezolizumab), another anti-PD-L1 mAb, proved effective in patients with metastatic urinary bladder cancer ${ }^{89}$ Based on favorable outcomes of clinical trials, the FDA approved atezolizumab for the treatment of urothelial carcinoma, certain types of metastatic lung cancer, and bladder cancer. ${ }^{82}$ In 2017, the FDA approved avelumab another anti-PD-L1 mAb - for the treatment of metastatic Merkel cell carcinoma and urothelial carcinoma. ${ }^{82}$ The effectiveness and safety of avelumab are currently under investigation in ovarian cancer, non-small-cell lung cancer, gastric cancer, and mesothelioma. ${ }^{90}$ Darvulumab, an antiPD-L1 mAb, was recently approved for the treatment of patients with advanced bladder cancer and for unresectable stage III non-small-cell lung cancer. ${ }^{82}$ Currently, the effectiveness of mAbs against the PD-1:PD-L1/2 pathway is being investigated in patients with nearly 250 different neoplastic disorders. ${ }^{67}$ Although several anti-PD-1 and antPD-L1 mAbs are approved, they have similar efficacy and toxicity profiles. ${ }^{91,92}$

\section{Blockade of CTLA-4}

At the end of the 20th century, studies showed that removing signals that blocked co-stimulation led to a stronger anticancer response. In mice with immunogenic colorectal cancer, treatment with anti-CTLA-4 mAbs before the transfer of tumor cells prevented disease development, mostly due to the activation of $\mathrm{CD}^{+} \mathrm{T}$ cells. Moreover, anti-CTLA-4 mAbs caused cancer regression in mice with developed tumors, including weakly immunogenic tumors. This treatment led to the formation of immunological memory against tumor cells..$^{93,94}$ Such encouraging preclinical findings prompted clinical trials with anti-CTLA-4 mAbs in patients with various neoplastic diseases. ${ }^{95}$ The effectiveness of ipilimumab, an anti-CTLA-4 $\mathrm{mAb}$, was investigated both as a standalone treatment and in combination with other treatments (IL-2, melanoma vaccine, and chemotherapy). ${ }^{96,97}$ In 2011, ipilimumab was approved by the FDA for the treatment of patients with advanced melanoma. Subsequently, in 2015, ipilimumab was approved as an adjuvant treatment in patients with melanoma after surgery and, in 2017, as a treatment for children with advanced melanoma. ${ }^{82,99}$ Ipilimumab is a promising treatment for relapsed and refractory B-cell non-Hodgkin lymphomas, metastatic renal cell carcinoma, small-cell and non-small-cell lung cancer, prostate cancer, urothelial carcinoma, and ovarian cancer. ${ }^{100}$ In phase I and phase II clinical trials in patients with metastatic melanoma, tremelimumab (ticilimumab), also an anti-CTLA-4 antibody, was associated with a durable tumor regression. ${ }^{101}$ Subsequently, the effect of tremelimumab was shown in patients with advanced gastric and esophageal adenocarcinoma, colorectal carcinoma, non-small-cell lung cancer, and malignant mesothelioma. ${ }^{63}$ Treatment with antiCTLA-4 mAbs such as ipilimumab and tremelimumab is associated with significant immune-related adverse effects. ${ }^{84}$ A high incidence of immune-related adverse events of antiCTLA-4 treatments is likely due to the depletion of Treg cells and a systemic activation of autoimmune $\mathrm{T}$ cells in the lymphoid tissue. ${ }^{56}$ Currently, approximately 300 clinical trials are investigating the effectiveness of ipilimumab and ipilimumab-combined therapies, and 100 clinical trials are investigating the effectiveness of tremelimumab and tremelimumab-combined therapies. ${ }^{67}$

\section{Blockade of LAG-3}

In ovarian and prostate cancers, LAG-3 is expressed by $\mathrm{CD}^{+}$tumor-specific $\mathrm{T}$ cells that co-express PD-1, which suggests that LAG-3 might be implicated in the formation of an immunosuppressive tumor microenvironment. ${ }^{102}$ In preclinical trials, LAG-3 blockade with mAbs was investigated as a standalone therapy and combined with anti-PD-1 and anti-CTLA-4 mAbs. ${ }^{103}$ In mice, the blockade of either PD-1 or LAG-3 did not effectively inhibit tumor development after transfer of cancer cells, but a dual blockade was more effective and was associated with higher percentages of $\mathrm{T} \mathrm{CD}^{+} /$ IFN $\gamma+$ and $\mathrm{CD}^{+}{ }^{+} \mathrm{T}$ cells. ${ }^{104}$ In another study, dual PD-1 and LAG-3 blockade caused a considerable tumor regression in all treated mice. ${ }^{105}$ A triple blockade of PD-1, CTLA-4, and LAG-3 significantly increased the effectiveness of cytotoxic T lymphocytes injected to mice with leukemia. ${ }^{106}$ However, targeting of multiple T-cell inhibitory molecules might be associated with an increased incidence of autoimmune adverse events. ${ }^{107}$ To date, two approaches to inhibit LAG-3 signaling have been developed: a LAG-3-Ig fusion protein and anti-LAG-3 mAbs (IMP321, LAG525, IMP701, TSR-033, REGN3767, and BMS-986016). ${ }^{22,108}$ Inhibition of LAG-3 may be effective not only due to the enhancement of Th1 responses, but also due to the stimulation of DC maturation, in which IL-12 is implicated. ${ }^{22}$ The effectiveness 
of IMP321 was shown in phase I clinical trials in patients with breast cancer, renal cell carcinoma, and pancreatic cancer. ${ }^{109-111}$ Currently, approximately 20 clinical trials are investigating anti-LAG-3 mAbs as a standalone treatment or combined with other therapies; bispecific proteins binding to PD-1 and LAG-3 are investigated in different metastatic cancers, small-cell lung cancer, gastrointestinal cancers, virus-associated tumors, hematologic neoplasms, brain tumors, and melanoma. ${ }^{67}$

\section{Blockade of TIM-3}

TIM-3-blocking mAbs enhance T-cell proliferation and increase cytokine production, which explains their antitumor activity. ${ }^{22}$ Tim $-3^{+}$tumor-infiltrating Tregs can greatly inhibit the proliferation of naïve T cells. ${ }^{12}$ In mice, anti-TIM-3 mAbs trigger an anticancer response, which is dependent mostly on $\mathrm{CD}^{+} \mathrm{T}$ cells that secrete IFN $\gamma$ and on $\mathrm{CD}^{+} \mathrm{T}$ cells. Although a substantial proportion of tumor-infiltrating CD4 ${ }^{+} \mathrm{TIM}^{-} 3^{+}$cells co-express Foxp3, the role of TIM-3 in Treg signaling remains unknown. ${ }^{113}$ In a mouse model of hepatitis B, TIM-3 blockade was associated with increased production of IFN $\gamma$ by $\mathrm{CD}^{+}$cells. ${ }^{114}$ Anti-TIM-3 antibodies slowed tumor growth in mice, which was associated with a decreased percentage of exhausted TIM-3 ${ }^{+}$lymphocytes. ${ }^{115}$ A more potent anticancer response was observed when antiTIM-3 mAbs were given in combination with anti-PD-1 or anti-CTLA-4 mAbs, when compared with the individual effects of these antibodies. ${ }^{116}$ The presence of TIM-3+ $\mathrm{T}$ cells correlates with disease severity and poor prognosis in patients with non-small-cell lung carcinoma and follicular lymphoma. ${ }^{22,117}$ In contrast, expression of galectin-9 - the main TIM-3 ligand - is associated with a favorable outcome in many solid tumors, which suggests that galectin- 9 may have other effects in cancer than those associated with TIM-3 signaling. ${ }^{118}$ Currently, anti-TIM-3 mAbs (MBG453, Sym023, TSR-022, and LY3321367) are being investigated in phase I and II clinical trials in patients with advanced malignancies, including leukemia; these treatments will be investigated in patients with solid tumors and lymphomas from June 2018 (six clinical trials). ${ }^{22,67}$

\section{Blockade of BTLA}

Tumor cells change the BTLA/HVEM signaling by either promoting the development of dysfunctional $\mathrm{T}$ cells with persistent BTLA expression (cells susceptible to inactivation) or by expressing HVEM - for example, in melanoma. ${ }^{22,119}$ In patients with advanced melanoma, BTLA is expressed by tumor-specific $\mathrm{CD}^{+} \mathrm{T}$ cells; moreover, an in vitro BTLA blockade of melanoma-specific $\mathrm{CD}^{+} \mathrm{T}$ cells increased their proliferation and secretion of IL-2, IFN $\gamma$, and TNF $\alpha$; these effects were even greater with a triple blockade (anti-BTLA, anti-PD-1, and anti-TIM-3). ${ }^{59}$ Both BTLA and HVEM are expressed by tumor cells and T-follicular helper cells in patients with chronic lymphocytic leukemia. These findings might direct the development of future immunotherapies. ${ }^{120}$ BTLA and HVEM are investigated as treatment targets in preclinical studies. ${ }^{56}$

\section{The place of immune-checkpoint inhibitors in cancer treatment}

Although several immune-checkpoint inhibitors are now available in clinical practice, the place of cancer immunotherapy is unclear. It is not often evident which patients will benefit from immune treatments more than from standard therapies. The choice between the immune and standard cancer treatments is even more difficult because the immune treatments are associated with a new class of adverse effects.

Based on the available data, a significant proportion of patients do not respond to treatment with immune-checkpoint inhibitors. Among patients with advanced melanoma, less than $20 \%$ respond to ipilimumab, approximately one third respond to pembrolizumab, and less than a half respond to nivolumab. ${ }^{121-123}$ When anti-CTLA-4 (ipilimumab) and antiPD-1 (nivolumab) treatments are given in combination, the response rate increases to approximately $60 \% .{ }^{124}$ The same treatment combination is associated with a response rate of approximately $40 \%-50 \%$ among patients with lung cancer. ${ }^{125}$ These observations suggest non-redundant effects of CTLA-4 and PD-1 blockade. ${ }^{123}$ For instance, $\mathrm{T}$ cells expressing CTLA-4 are found predominantly in secondary lymphoid organs, whereas PD-1 expression is characteristic for T cells in the tumor microenvironment. ${ }^{126}$ Moreover, CTLA-4 targets mostly recently primed cells, and PD-1 targets primarily effector T cells. ${ }^{126}$ Furthermore, CTLA-4 and PD-1 have different intracellular signaling pathways (Figure 1).

It is important to establish predictive factors for selecting patients who will most likely benefit from immunotherapy. In general, it is believed that patients with tumors that are well infiltrated by immune cells (hot tumors) respond to immunotherapy better than patients with tumors that display scarce immune infiltration (cold tumors). Infiltration of tumors by immune cells depends both on tumor immunogenicity and on host immune function. For example, immunogenic tumors - that is, those characterized by a high mutational load and, thus, a high neoantigen load - respond well to 
immune-checkpoint inhibitors. ${ }^{126}$ Similarly, high counts of circulating immune cells with proliferative potential $\left(\mathrm{CD} 8^{+}\right.$ $\mathrm{Ki} 67+$ ), relative to tumor burden, are associated with a favorable response to immune-checkpoint inhibition. ${ }^{127}$ Moreover, expression of immune-checkpoint ligands by tumors seems important, because immune-checkpoint inhibitors are thought to act by competing with its ligands. Indeed, high concentrations of PD-L1 are associated with a favorable clinical response to PD-1 blockade. ${ }^{128,129}$ In line with this observation, in patients with urothelial cancer who have a low PD-L1 status, the effects of PD-1 blockade are worse than those of chemotherapy. ${ }^{130}$ Other predictors of clinical response to immune-checkpoint inhibitors are being investigated. For example, a recent study showed that patients with melanoma who responded to anti-PD-1 immunotherapy had different gut microbiome than did non-responders. ${ }^{131}$

Immune-checkpoint inhibitors are associated with a new class of immune-mediated adverse events. In general, immune-related adverse effects occur more commonly with anti-CTLA-4 blockade ( $50 \%)$ than with anti-PD-1 blockade $(\sim 25 \%) .{ }^{132}$ Moreover, the frequency of immune-related adverse effects is higher with a combination of CTLA-4 and PD-1 blockade. However, patients with advanced cancer seem to better tolerate PD-1/PD-L1 blockade than chemotherapy. ${ }^{133}$ The immune-related adverse effects are due to immune overactivation, and they include skin changes, diarrhea related to colitis, hepatotoxicity, pneumonitis, and different endocrinopathies such as autoimmune thyroid disease (hypothyroidism and hyperthyroidism), hypophysitis, adrenal insufficiency, and type 1 diabetes mellitus. These adverse effects are usually managed with glucocorticoids, which, in turn, may cause infections such as tuberculosis. ${ }^{134}$ The adverse effects of immune-checkpoint inhibitors are often severe and lead to treatment discontinuation. For example, approximately half the patients who received adjuvant ipilimumab after surgery for melanoma discontinued treatment due to adverse effects. ${ }^{135}$ Thus, the adverse effects of immune-checkpoint inhibitors should be weighed against their expected benefit, particularly when considering combined CTLA-4 and PD-1 blockade. Although this combined treatment is more effective than its individual components, it is associated with the highest risk of immune-related adverse effects.

\section{Conclusion}

In most advanced cancers, chemotherapy is possibly approaching or has already reached the greatest possible therapeutic effect. The different methods used to overcome T-cell dysfunction have proved effective in some cancers, and this approach might replace chemotherapy in the future. Treatments aimed at boosting immune function have several advantages over other treatments, such as a relatively short treatment period (several weeks). Moreover, they do not need to be specifically prepared for each individual patient (like DC vaccines). Some of these treatments are already approved on the basis of encouraging outcomes of clinical trials. Cancer immunotherapy has lower toxicity compared with chemotherapy; in some cancers, it may achieve a longterm disease control. Currently, finding reliable response factors to immunotherapy is crucial to properly select the best treatment for each patient. Treatment with mAbs that boost immune function, particularly a simultaneous use of antibodies that target different mechanisms of T-cell exhaustion, in combination with other treatments, shows the greatest promise for patients with cancer, including those with cancer resistant to standard therapies.

\section{Acknowledgments}

This work was supported by the Polish National Science Center (grant no UMO-2016/21/B/NZ6/02279) and the Medical University of Lublin (grant no DS460). The sponsors had no role in study design, data collection and analysis, decision to publish, or preparation of the manuscript.

\section{Disclosure}

The authors report no conflicts of interest in this work.

\section{References}

1. Goral S. The three-signal hypothesis of lymphocyte activation/targets for immunosuppression. Dial Transplant. 2011;40(1):14-16.

2. Qi X, Jia B, Zhao X, Yu D. Advances in T-cell checkpoint immunotherapy for head and neck squamous cell carcinoma. OncoTargets Ther. 2017; 10:5745-5754.

3. Pauken KE, Wherry EJ. Overcoming T cell exhaustion in infection and cancer. Trends Immunol. 2015;36(4):265-276.

4. Thommen DS, Schumacher TN. T Cell Dysfunction in Cancer. Cancer Cell. 2018;33(4):547-562.

5. Wherry EJ, Kurachi M. Molecular and cellular insights into T cell exhaustion. Nat Rev Immunol. 2015;15(8):486-499.

6. Mueller SN, Ahmed R. High antigen levels are the cause of T cell exhaustion during chronic viral infection. Proc Natl Acad Sci U S A. 2009;106(21):8623-8628.

7. Własiuk P, Putowski M, Giannopoulos K. PD1/PD1L pathway, HLA-G and $\mathrm{T}$ regulatory cells as new markers of immunosuppression in cancers. Postępy Hig Med Dośw (online). 2016;70:1044-1058.

8. Balkhi MY, Ma Q, Ahmad S, Junghans RP. T cell exhaustion and Interleukin 2 downregulation. Cytokine. 2015;71(2):339-347.

9. Chłopek M, Kowalik A, Góźdź S, Koziak K. The role of interleukin 15 in neoplasia. Postepy Hig Med Dosw (online). 2017;71(0): 5-19. 
10. Grenier JM, Yeung ST, Khanna KM. Combination Immunotherapy: Taking Cancer Vaccines to the Next Level. Front Immunol. 2018;9:610.

11. Crusz SM, Balkwill FR. Inflammation and cancer: advances and new agents. Nat Rev Clin Oncol. 2015;12(10):584-596.

12. Kumar R, Yu F, Zhen YH, et al. PD-1 blockade restores impaired function of ex vivo expanded CD8+ T cells and enhances apoptosis in mismatch repair deficient EpCAM+PD-L1+. OncoTargets Ther. 2017; 10:3453-3465

13. Ha SJ, West EE, Araki K, Smith KA, Ahmed R. Manipulating both the inhibitory and stimulatory immune system towards the success of therapeutic vaccination against chronic viral infections. Immunol Rev. 2008;223(1):317-333.

14. Crespo J, Sun H, Welling TH, Tian Z, Zou W. T cell anergy, exhaustion, senescence, and stemness in the tumor microenvironment. Curr Opin Immunol. 2013;25(2):214-221.

15. Eleftheriadis T, Antoniadi G, Liakopoulos V, Kortsaris A. T-Cell Zeta Chain Expression, Phosphorylation and Degradation and their Role in T-Cell Signal Transduction and Immune Response Regulation in Health And Disease. Curr Signal Transduct Ther. 2006;1(2): 191-208.

16. Torelli GF, Paolini R, Tatarelli C, et al. Defective expression of the $\mathrm{T}$-cell receptor-CD3 zeta chain in T-cell acute lymphoblastic leukaemia. Br J Haematol. 2003;120(2):201-208.

17. Cornwell WD, Rogers TJ. Uncoupling of T cell receptor zeta chain function during the induction of anergy by the superantigen, staphylococcal enterotoxin A. Toxins. 2010;2(7):1704-1717.

18. Ishida Y, Agata Y, Shibahara K, Honjo T. Induced expression of PD-1, a novel member of the immunoglobulin gene superfamily, upon programmed cell death. Embo J. 1992;11(11):3887-3895.

19. Okazaki T, Maeda A, Nishimura H, Kurosaki T, Honjo T. PD-1 immunoreceptor inhibits B cell receptor-mediated signaling by recruiting src homology 2-domain-containing tyrosine phosphatase 2 to phosphotyrosine. Proc Natl Acad Sci U S A. 2001;98(24):13866-13871.

20. Patsoukis N, Sari D, Boussiotis VA. PD-1 inhibits T cell proliferation by upregulating p27 and p15 and suppressing Cdc25A. Cell Cycle. 2012;11(23):4305-4309.

21. Krueger J, Rudd CE. Two Strings in One Bow: PD-1 Negatively Regulates via Co-receptor CD28 on T Cells. Immunity. 2017;46(4):529-531.

22. Marin-Acevedo JA, Dholaria B, Soyano AE, Knutson KL, Chumsri S, Lou Y. Next generation of immune checkpoint therapy in cancer: new developments and challenges. J Hematol Oncol. 2018;11(1):39.

23. Chemnitz JM, Parry RV, Nichols KE, June CH, Riley JL. SHP-1 and SHP-2 associate with immunoreceptor tyrosine-based switch motif of programmed death 1 upon primary human T cell stimulation, but only receptor ligation prevents T cell activation. J Immunol. 2004;173(2): 945-954.

24. Lichtenegger FS, Rothe M, Schnorfeil FM, et al. Targeting LAG-3 and PD-1 to Enhance T Cell Activation by Antigen-Presenting Cells. Front Immunol. 2018;9:385.

25. Wong RM, Smith KA, Tam VL, et al. TLR-9 signaling and TCR stimulation co-regulate CD8+ T cell-associated PD-1 expression. Immunol Lett. 2009;127(1):60-67.

26. Heim L, Friedrich J, Engelhardt M, et al. NFATc1 promotes anti-tumoral effector functions and memory $\mathrm{CD}^{+} \mathrm{T}$ cell differentiation during non-small cell lung cancer development. Cancer Res. 2018;78(13):3619-3633.

27. Freeman GJ, Long AJ, Iwai Y, et al. Engagement of the Pd-1 Immunoinhibitory Receptor by a Novel B7 Family Member Leads to Negative Regulation of Lymphocyte Activation. J Exp Med. 2000;192(7):1027-1034.

28. Gianchecchi E, Delfino DV, Fierabracci A. Recent insights into the role of the PD-1/PD-L1 pathway in immunological tolerance and autoimmunity. Autoimmun Rev. 2013;12(11):1091-1100.

29. Liechtenstein T, Dufait I, Bricogne C, et al. PD-L1/PD-1 Co-Stimulation, a Brake for $\mathrm{T}$ cell Activation and a $\mathrm{T}$ cell Differentiation Signal. J Clin Cell Immunol. 2012;S12.
30. Keir ME, Latchman YE, Freeman GJ, Sharpe AH. Programmed death-1 (PD-1):PD-ligand 1 interactions inhibit TCR-mediated positive selection of thymocytes. J Immunol. 2005;175(11):7372-7379.

31. Pauken KE, Jenkins MK, Azuma M, Fife BT. PD-1, but Not PD-L1, Expressed by Islet-Reactive CD4 ${ }^{+}$T Cells Suppresses Infiltration of the Pancreas During Type 1 Diabetes. Diabetes. 2013;62(8):2859-2869.

32. Pianta S, Magatti M, Vertua E, et al. Amniotic mesenchymal cells from pre-eclamptic placentae maintain immunomodulatory features as healthy controls. J Cell Mol Med. 2016;20(1):157-169.

33. Hirose T, Tanaka Y, Tanaka A, et al. PD-L1/PD-L2-expressing B-1 cells inhibit alloreactive T cells in mice. PLoS One. 2017;12(6):e0178765.

34. Nie X, Chen W, Zhu Y, et al. B7-DC (PD-L2) costimulation of CD4+ T-helper 1 response via RGMb. Cell Mol Immunol. Epub 2017 May 8.

35. Zhong X, Tumang JR, Gao W, Bai C, Rothstein TL. PD-L2 expression extends beyond dendritic cells/macrophages to B1 cells enriched for $\mathrm{V}(\mathrm{H}) 11 / \mathrm{V}(\mathrm{H}) 12$ and phosphatidylcholine binding. Eur J Immunol. 2007;37(9):2405-2410.

36. Saunders PA, Hendrycks VR, Lidinsky WA, Woods ML. PD-L2:PD-1 involvement in $\mathrm{T}$ cell proliferation, cytokine production, and integrinmediated adhesion. Eur J Immunol. 2005;35(12):3561-3569.

37. Ramos-Hernández N, Ramon HE, Beal AM, Laroche A, Dekleva EA, Oliver PM. Ndfip1 enforces a requirement for CD28 costimulation by limiting IL-2 production. J Immunol. 2013;191(4):1536-1546.

38. Francisco LM, Salinas VH, Brown KE, et al. PD-L1 regulates the development, maintenance, and function of induced regulatory T cells. J Exp Med. 2009;206(13):3015-3029.

39. Sakaguchi S, Wing K, Onishi Y, Prieto-Martin P, Yamaguchi T. Regulatory T cells: how do they suppress immune responses? Int Immunol. 2009;21(10):1105-1111.

40. Tai X, van Laethem F, Pobezinsky L, et al. Basis of CTLA-4 function in regulatory and conventional CD4+ T cells. Blood. 2012;119(22): 5155-5163.

41. Klepsch V, Hermann-Kleiter N, Baier G. Beyond CTLA-4 and PD-1: Orphan nuclear receptor NR2F6 as T cell signaling switch and emerging target in cancer immunotherapy. Immunol Lett. 2016;178:31-36.

42. Carreno BM, Bennett F, Chau TA, et al. CTLA-4 (CD152) can inhibit $\mathrm{T}$ cell activation by two different mechanisms depending on its level of cell surface expression. J Immunol. 2000;165(3): 1352-1356.

43. Ciszak L, Frydecka I, Wolowiec D, Szteblich A, Kosmaczewska A. CTLA-4 affects expression of key cell cycle regulators of $\mathrm{G} 0 / \mathrm{G} 1$ phase in neoplastic lymphocytes from patients with chronic lymphocytic leukaemia. Clin Exp Med. 2016;16(3):317-332.

44. Zhang ZM, Yang XM, Zhang C, et al. Antitumor effects and mechanisms of dendritic cells stimulated by SCD40L on ovarian cancer cells in vitro. OncoTargets Ther. 2013;6:503-515.

45. Dyck L, Mills KHG. Immune checkpoints and their inhibition in cancer and infectious diseases. Eur J Immunol. 2017;47(5):765-779.

46. Andrews LP, Marciscano AE, Drake CG, Vignali DAA. LAG3 (CD223) as a cancer immunotherapy target. Immunol Rev. 2017;276(1):80-96.

47. Grosso JF, Kelleher CC, Harris TJ, et al. LAG-3 regulates CD8+ T cell accumulation and effector function in murine self- and tumor-tolerance systems. J Clin Invest. 2007;117(11):3383-3392.

48. Huang CT, Workman CJ, Flies D, et al. Role of LAG-3 in Regulatory T Cells. Immunity. 2004;21(4):503-513.

49. Grosso JF, Goldberg MV, Getnet D, et al. Functionally distinct LAG-3 and PD-1 subsets on activated and chronically stimulated CD8 T cells. J Immunol. 2009;182(11):6659-6669.

50. Lajko A, Meggyes M, Polgar B, Szereday L. The immunological effect of Galectin-9/TIM-3 pathway after low dose Mifepristone treatment in mice at 14.5 day of pregnancy. PLoS One. 2018;13(3):e0194870.

51. Ngiow SF, Teng MWL, Smyth MJ. Prospects for TIM3-Targeted Antitumor Immunotherapy. Cancer Res. 2011;71(21):6567-6571.

52. Kashio Y, Nakamura K, Abedin MJ, et al. Galectin-9 induces apoptosis through the calcium-calpain-caspase-1 pathway. J Immunol. $2003 ; 170(7): 3631-3636$. 
53. Zhu C, Anderson AC, Schubart A, et al. The Tim-3 ligand galectin-9 negatively regulates Thelper type 1 immunity. Nat Immunol. 2005;6(12): $1245-1252$.

54. Koohini Z, Hossein-Nataj H, Mobini M, Hosseinian-Amiri A, Rafiei A, Asgarian-Omran H. Analysis of PD-1 and Tim-3 expression on CD4+ $\mathrm{T}$ cells of patients with rheumatoid arthritis; negative association with DAS28. Clin Rheumatol. 2018;37(8):2063-2071.

55. Peng P-Ji, Li Y, Sun S. On the significance of Tim-3 expression in pancreatic cancer. Saudi J Biol Sci. 2017;24(8):1754-1757.

56. Torphy R, Schulick R, Zhu Y. Newly Emerging Immune Checkpoints: Promises for Future Cancer Therapy. Int J Mol Sci. 2017; 18(12):2642.

57. Wang $\mathrm{Z}$, Wang $\mathrm{K}$, Yang $\mathrm{H}$, et al. Associations between HVEM/ LIGHT/BTLA/CD160 polymorphisms and the occurrence of antibody-mediate rejection in renal transplant recipients. Oncotarget. 2017;8(59):100079-100094.

58. Pilat N, Sayegh MH, Wekerle T. Costimulatory pathways in transplantation. Semin Immunol. 2011;23(4):293-303.

59. Fourcade J, Sun Z, Pagliano O, et al. CD8(+) T cells specific for tumor antigens can be rendered dysfunctional by the tumor microenvironment through upregulation of the inhibitory receptors BTLA and PD-1. Cancer Res. 2012;72(4):887-896.

60. Pasero C, Olive D. Interfering with coinhibitory molecules: BTLA/ HVEM as new targets to enhance anti-tumor immunity. Immunol Lett. 2013;151(1-2):71-75.

61. Janakiram M, Shah UA, Liu W, Zhao A, Schoenberg MP, Zang X. The third group of the B7-CD28 immune checkpoint family: HHLA2, TMIGD2, B7x, and B7-H3. Immunol Rev. 2017;276(1):26-39.

62. Liu J, Yuan Y, Chen W, et al. Immune-checkpoint proteins VISTA and PD-1 nonredundantly regulate murine T-cell responses. Proc Natl Acad Sci U S A. 2015;112(21):6682-6687.

63. Catakovic K, Klieser E, Neureiter D, Geisberger R. T cell exhaustion: from pathophysiological basics to tumor immunotherapy. Cell Commun Signal. 2017;15(1):1.

64. Shao Y, Zhu W, Da J, et al. Bisdemethoxycurcumin in combination with alpha-PD-L1 antibody boosts immune response against bladder cancer. OncoTargets Ther. 2017;10:2675-2683.

65. Liu Q, Hu P, Deng G, et al. Soluble cytotoxic T-lymphocyte antigen 4: a favorable predictor in malignant tumors after therapy. OncoTargets Ther. 2017;10:2147-2154.

66. Swatler J, Kozłowska E. Immune checkpoint-targeted cancer immunotherapies. Postępy Hig Med Dośw (online). 2016;70: $25-42$.

67. Clinical Trials. Available from: https://clinicaltrials.gov/ct2/results? cond $=\&$ term $=$ immune + checkpoint + inhibitor $\&$ cntry $=\&$ state $=\& c i t y=$ \&dist $=$. Accessed July 28, 2018.

68. Karim R, Jordanova ES, Piersma SJ, et al. Tumor-Expressed B7-H1 and B7-DC in Relation to PD-1+ T-Cell Infiltration and Survival of Patients with Cervical Carcinoma. Clin Cancer Res. 2009;15(20):6341-6347.

69. Larbcharoensub N, Mahaprom K, Jiarpinitnun C, et al. Characterization of PD-L1 and PD-1 Expression and CD8 Tumor-infiltrating Lymphocyte in Epstein-Barr Virus-associated Nasopharyngeal Carcinoma. Am J Clin Oncol. Epub 2018 Apr 18.

70. Yearley JH, Gibson C, Yu N, et al. PD-L2 Expression in Human Tumors: Relevance to Anti-PD-1 Therapy in Cancer. Clin Cancer Res. 2017;23(12):3158-3167.

71. Muenst S, Soysal SD, Gao F, Obermann EC, Oertli D, Gillanders WE. The presence of programmed death 1 (PD-1)-positive tumor-infiltrating lymphocytes is associated with poor prognosis in human breast cancer. Breast Cancer Res Treat. 2013;139(3):667-676.

72. Chen CL, Pan QZ, Weng DS, et al. Safety and activity of PD-1 blockade-activated DC-CIK cells in patients with advanced solid tumors. Oncoimmunology. 2018;7(4):e1417721.

73. Kodumudi KN, Siegel J, Weber AM, Scott E, Sarnaik AA, PilonThomas S. Immune Checkpoint Blockade to Improve Tumor Infiltrating Lymphocytes for Adoptive Cell Therapy. PLoS One. 2016;11(4): e0153053.
74. Taube JM, Anders RA, Young GD, et al. Colocalization of inflammatory response with B7-h1 expression in human melanocytic lesions supports an adaptive resistance mechanism of immune escape. Sci Transl Med. 2012;4(127):ra37.

75. Lamichhane P, Karyampudi L, Shreeder B, et al. IL10 Release upon PD-1 Blockade Sustains Immunosuppression in Ovarian Cancer. Cancer Res. 2017;77(23):6667-6678.

76. Dong L, Zheng X, Wang K, Wang G, Zou H. PD-1/PD-L1 pathway participates in gastric surgery-induced imbalance of Th17/Treg cells in mice. J Trauma Acute Care Surg. 2018;85(3):549-559.

77. Iwai Y, Ishida M, Tanaka Y, Okazaki T, Honjo T, Minato N. Involvement of PD-L1 on tumor cells in the escape from host immune system and tumor immunotherapy by PD-L1 blockade. Proc Natl Acad Sci U S A. 2002;99(19):12293-12297.

78. Brahmer JR, Drake CG, Wollner I, et al. Phase I study of single-agent anti-programmed death-1 (MDX-1106) in refractory solid tumors: safety, clinical activity, pharmacodynamics, and immunologic correlates. J Clin Oncol. 2010;28(19):3167-3175.

79. Topalian SL, Hodi FS, Brahmer JR, et al. Safety, Activity, and Immune Correlates of Anti-PD-1 Antibody in Cancer. NEngl JMed Overseas Ed. 2012;366(26):2443-2454.

80. Overman MJ, McDermott R, Leach JL, et al. Nivolumab in patients with metastatic DNA mismatch repair-deficient or microsatellite instabilityhigh colorectal cancer (CheckMate 142): an open-label, multicentre, phase 2 study. Lancet Oncol. 2017;18(9):1182-1191.

81. Ansell SM, Lesokhin AM, Borrello I, et al. PD-1 Blockade with Nivolumab in Relapsed or Refractory Hodgkin's Lymphoma. N Engl J Med Overseas Ed. 2015;372(4):311-319.

82. Resources for Information on Approved Drugs. Available from: https:// www.fda.gov/Drugs/InformationOnDrugs/ApprovedDrugs/default. htm. Accessed July 28, 2018.

83. Robert C, Ribas A, Wolchok JD, et al. Anti-programmed-death-receptor-1 treatment with pembrolizumab in ipilimumab-refractory advanced melanoma: a randomised dose-comparison cohort of a phase 1 trial. The Lancet. 2014;384(9948):1109-1117.

84. Sosa A, Lopez Cadena E, Simon Olive C, Karachaliou N, Rosell R. Clinical assessment of immune-related adverse events. Ther $A d v$ Med Oncol. 2018;10:175883591876462.

85. Robert C, Schachter J, Long GV, et al. Pembrolizumab versus Ipilimumab in Advanced Melanoma. $N$ Engl $J$ Med Overseas Ed. 2015;372(26):2521-2532

86. Armand P, Nagler A, Weller EA, et al. Disabling immune tolerance by programmed death-1 blockade with pidilizumab after autologous hematopoietic stem-cell transplantation for diffuse large B-cell lymphoma: results of an international phase II trial. J Clin Oncol. 2013; 31(33):4199-4206.

87. Westin JR, Chu F, Zhang M, et al. Safety and activity of PD1 blockade by pidilizumab in combination with rituximab in patients with relapsed follicular lymphoma: a single group, open-label, phase 2 trial. Lancet Oncol. 2014;15(1):69-77.

88. Brahmer JR, Tykodi SS, Chow LQM, et al. Safety and Activity of Anti-PD-L1 Antibody in Patients with Advanced Cancer. $N$ Engl $J$ Med Overseas Ed. 2012;366(26):2455-2465.

89. Inman BA, Longo TA, Ramalingam S, Harrison MR. Atezolizumab: A PD-L1-Blocking Antibody for Bladder Cancer. Clin Cancer Res. 2017;23(8):1886-1890.

90. Kelly K, Infante JR, Taylor MH, et al. Safety profile of avelumab in patients with advanced solid tumors: A pooled analysis of data from the phase 1 JAVELIN solid tumor and phase 2 JAVELIN Merkel 200 clinical trials. Cancer. 2018;124(9):2010-2017.

91. Pillai RN, Behera M, Owonikoko TK, et al. Comparison of the toxicity profile of PD-1 versus PD-L1 inhibitors in non-small cell lung cancer: A systematic analysis of the literature. Cancer. 2018;124(2): 271-277.

92. Prasad V, Kaestner V. Nivolumab and pembrolizumab: Monoclonal antibodies against programmed cell death-1 (PD-1) that are interchangeable. Semin Oncol. 2017;44(2):132-135. 
93. Leach DR, Krummel MF, Allison JP. Enhancement of Antitumor Immunity by CTLA-4 Blockade. Science. 1996;271(5256):1734-1736.

94. van Elsas A, Hurwitz AA, Allison JP. Combination immunotherapy of B16 melanoma using anti-cytotoxic T lymphocyte-associated antigen 4 (CTLA-4) and granulocyte/macrophage colony-stimulating factor (GM-CSF)-producing vaccines induces rejection of subcutaneous and metastatic tumors accompanied by autoimmune depigmentation. J Exp Med. 1999;190(3):355-366.

95. Maker AV, Phan GQ, Attia P, et al. Tumor regression and autoimmunity in patients treated with cytotoxic T lymphocyte-associated antigen 4 blockade and interleukin 2: a phase I/II study. Ann Surg Oncol. 2005;12(12):1005-1016.

96. Wolchok JD, Hodi FS, Weber JS, et al. Development of ipilimumab: a novel immunotherapeutic approach for the treatment of advanced melanoma. Ann N Y Acad Sci. 2013;1291(1):1-13.

97. O’Day SJ, Maio M, Chiarion-Sileni V, et al. Efficacy and safety of ipilimumab monotherapy in patients with pretreated advanced melanoma: a multicenter single-arm phase $\{$ II $\}$ study. Ann Oncol. 2010;21(8):1712-1717.

98. Postow MA, Yuan J, Kitano S, Lesokhin AM, Wolchok JD. Markers for anti-cytotoxic T-lymphocyte antigen 4 (CTLA-4) therapy in melanoma. Methods Mol Biol. 2014;1102:83-95.

99. Dréno B. Ipilimumab more and more discussed: Urgent need for predictive markers of response. J Eur Acad Dermatology Venereol. 2018;32(6):849.

100. Wang RF, Wang HY. Immune targets and neoantigens for cancer immunotherapy and precision medicine. Cell Res. 2017;27(1):11-37.

101. Ribas A. Clinical development of the anti-CTLA-4 antibody tremelimumab. Semin Oncol. 2010;37(5):450-454.

102. Cappuccini F, Pollock E, Stribbling S, Hill AVS, Redchenko I. 5T4 oncofoetal glycoprotein: an old target for a novel prostate cancer immunotherapy. Oncotarget. 2017;8(29):47474-47489.

103. Hellmann MD, Friedman CF, Wolchok JD. Combinatorial cancer immunotherapies. Adv Immunol. 2016;130:251-277.

104. Woo SR, Turnis ME, Goldberg MV, et al. Immune inhibitory molecules LAG-3 and PD-1 synergistically regulate T-cell function to promote tumoral immune escape. Cancer Res. 2012;72(4): 917-927.

105. Foy SP, Sennino B, dela Cruz T, et al. Poxvirus-Based Active Immunotherapy with PD-1 and LAG-3 Dual Immune Checkpoint Inhibition Overcomes Compensatory Immune Regulation, Yielding Complete Tumor Regression in Mice. PLoS One. 2016;11(2):e0150084.

106. Berrien-Elliott MM, Jackson SR, Meyer JM, et al. Durable adoptive immunotherapy for leukemia produced by manipulation of multiple regulatory pathways of CD8+ T-cell tolerance. Cancer Res. 2013; 73(2):605-616.

107. Pardoll DM. The blockade of immune checkpoints in cancer immunotherapy. Nat Rev Cancer. 2012;12(4):252-264.

108. Sharma P, Allison JP. Immune checkpoint targeting in cancer therapy: toward combination strategies with curative potential. Cell. 2015;161(2):205-214.

109. Brignone C, Escudier B, Grygar C, Marcu M, Triebel F. A phase I pharmacokinetic and biological correlative study of IMP321, a novel MHC class II agonist, in patients with advanced renal cell carcinoma. Clin Cancer Res. 2009;15(19):6225-6231.

110. Brignone C, Gutierrez M, Mefti F, et al. First-line chemoimmunotherapy in metastatic breast carcinoma: combination of paclitaxel and IMP321 (LAG-3Ig) enhances immune responses and antitumor activity. J Transl Med. 2010;8(1):71.

111. Wang-Gillam A, Plambeck-Suess S, Goedegebuure P, et al. A phase I study of IMP321 and gemcitabine as the front-line therapy in patients with advanced pancreatic adenocarcinoma. Invest New Drugs. 2013; 31(3):707-713.

112. Liu Z, McMichael EL, Shayan G, et al. Novel effector phenotype of Tim-3 regulatory $T$ cells leads to enhanced suppressive function in head and neck cancer patients. Clin Cancer Res. 2018;24(18):4529-4538.
113. Du W, Yang M, Turner A, et al. TIM-3 as a Target for Cancer Immunotherapy and Mechanisms of Action. Int J Mol Sci. 2017;18(3):645.

114. Ju Y, Hou N, Zhang XN, et al. Blockade of Tim-3 pathway ameliorates interferon-gamma production from hepatic $\mathrm{CD} 8+\mathrm{T}$ cells in a mouse model of hepatitis B virus infection. Cell Mol Immunol. 2009;6(1): 35-43.

115. Ngiow SF, von Scheidt B, Akiba H, Yagita H, Teng MW, Smyth MJ. Anti-TIM3 antibody promotes T cell IFN- $\gamma$-mediated antitumor immunity and suppresses established tumors. Cancer Res. 2011;71(10): $3540-3551$.

116. Perez-Gracia JL, Labiano S, Rodriguez-Ruiz ME, Sanmamed MF, Melero I. Orchestrating immune check-point blockade for cancer immunotherapy in combinations. Curr Opin Immunol. 2014;27:89-97.

117. Anderson AC, Joller N, Kuchroo VK. Lag-3, Tim-3, and TIGIT: Co-inhibitory Receptors with Specialized Functions in Immune Regulation. Immunity. 2016;44(5):989-1004.

118. Zhou X, Sun L, Jing D, et al. Galectin-9 Expression Predicts Favorable Clinical Outcome in Solid Tumors: A Systematic Review and Meta-Analysis. Front Physiol. 2018;9:452.

119. Paulos CM, June CH. Putting the brakes on BTLA in T cell-mediated cancer immunotherapy. J Clin Invest. 2010;120(1):76-80.

120. M'Hidi H, Thibult ML, Chetaille B, et al. High expression of the inhibitory receptor BTLA in T-follicular helper cells and in B-cell small lymphocytic lymphoma/chronic lymphocytic leukemia. Am J Clin Pathol. 2009;132(4):589-596.

121. Fellner C, Ipilimumab FC. Ipilimumab (yervoy) prolongs survival in advanced melanoma: serious side effects and a hefty price tag may limit its use. $P$ T. 2012;37(9):503-530.

122. Ribas A, Hamid O, Daud A, et al. Association of Pembrolizumab With Tumor Response and Survival Among Patients With Advanced Melanoma. JAMA. 2016;315(15):1600.

123. Larkin J, Chiarion-Sileni V, Gonzalez R, et al. Combined Nivolumab and Ipilimumab or Monotherapy in Untreated Melanoma. $N$ Engl $J$ Med. 2015;373(1):23-34.

124. Long GV, Atkinson V, Cebon JS, et al. Standard-dose pembrolizumab in combination with reduced-dose ipilimumab for patients with advanced melanoma (KEYNOTE-029): an open-label, phase $1 \mathrm{~b}$ trial. Lancet Oncol. 2017;18(9):1202-1210.

125. Hellmann MD, Rizvi NA, Goldman JW, et al. Nivolumab plus ipilimumab as first-line treatment for advanced non-small-cell lung cancer (CheckMate 012): results of an open-label, phase 1, multicohort study. Lancet Oncol. 2017;18(1):31-41.

126. Zappasodi R, Merghoub T, Wolchok JD. Emerging Concepts for Immune Checkpoint Blockade-Based Combination Therapies. Cancer Cell. 2018;33(4):581-598.

127. Huang AC, Postow MA, Orlowski RJ, et al. T-cell invigoration to tumour burden ratio associated with anti-PD-1 response. Nature. 2017;545(7652):60-65.

128. Herbst RS, Soria JC, Kowanetz M, et al. Predictive correlates of response to the anti-PD-L1 antibody MPDL3280A in cancer patients. Nature. 2014;515(7528):563-567.

129. Garon EB, Rizvi NA, Hui R, et al. Pembrolizumab for the treatment of non-small-cell lung cancer. N Engl J Med. 2015;372(21): 2018-2028.

130. Safety Alerts for Human Medical Products. Keytruda (pembrolizumab) or Tecentriq (atezolizumab): FDA Alerts Health Care Professionals and Investigators: FDA Statement - Decreased Survival in Some Patients in Clinical Trials Associated with Monotherapy. Available from: https:// www.fda.gov/Safety/MedWatch/SafetyInformation/SafetyAlertsforHumanMedicalProducts/ucm608253.htm. Accessed July 28, 2018.

131. Gopalakrishnan V, Spencer CN, Nezi L, et al. Gut microbiome modulates response to anti-PD-1 immunotherapy in melanoma patients. Science. 2018;359(6371):97-103.

132. El Osta B, Hu F, Sadek R, Chintalapally R, Tang SC. Not all immunecheckpoint inhibitors are created equal: Meta-analysis and systematic review of immune-related adverse events in cancer trials. Crit Rev Oncol Hematol. 2017;119:1-12. 
133. Nishijima TF, Shachar SS, Nyrop KA, Muss HB. Safety and Tolerability of PD-1/PD-L1 Inhibitors Compared with Chemotherapy in Patients with Advanced Cancer: A Meta-Analysis. Oncologist. 2017; 22(4):470-479.

134. Picchi $\mathrm{H}$, Mateus $\mathrm{C}$, Chouaid $\mathrm{C}$, et al. Infectious complications associated with the use of immune checkpoint inhibitors in oncology: reactivation of tuberculosis after anti PD-1 treatment. Clin Microbiol Infect. 2018;24(3):216-218.
135. Eggermont AM, Chiarion-Sileni V, Grob JJ, et al. Adjuvant ipilimumab versus placebo after complete resection of high-risk stage III melanoma (EORTC 18071): a randomised, double-blind, phase 3 trial. Lancet Oncol. 2015;16(5):522-530.

\section{Publish your work in this journal}

OncoTargets and Therapy is an international, peer-reviewed, open access journal focusing on the pathological basis of all cancers, potential targets for therapy and treatment protocols employed to improve the management of cancer patients. The journal also focuses on the impact of management programs and new therapeutic agents and protocols on

\section{Dovepress}

patient perspectives such as quality of life, adherence and satisfaction. The manuscript management system is completely online and includes a very quick and fair peer-review system, which is all easy to use. Visit http://www.dovepress.com/testimonials.php to read real quotes from published authors. 